\title{
max \\ Thermal Analysis and Kinetic Modeling of Pyrolysis and Oxidation of Hydrochars
}

\author{
Gabriella Gonnella ${ }^{1}$, Giulia Ischia ${ }^{1} \mathbb{D}$, Luca Fambri ${ }^{2} \mathbb{D}$ and Luca Fiori ${ }^{1, * \mathbb{C}}$ \\ 1 Department of Civil, Environmental and Mechanical Engineering, University of Trento, 38123 Trento, Italy; \\ ga.gonnella@gmail.com (G.G.); giulia.ischia-1@unitn.it (G.I.) \\ 2 Department of Industrial Engineering, University of Trento, Via Sommarive 9, 38123 Trento, Italy; \\ luca.fambri@unitn.it \\ * Correspondence: luca.fiori@unitn.it
}

check for updates

Citation: Gonnella, G.; Ischia, G.; Fambri, L.; Fiori, L. Thermal Analysis and Kinetic Modeling of Pyrolysis and Oxidation of Hydrochars. Energies 2022, 15, 950. https:// doi.org/10.3390/en15030950

Academic Editors: M. Toufiq Reza and Javier Fermoso

Received: 30 December 2021

Accepted: 24 January 2022

Published: 27 January 2022

Publisher's Note: MDPI stays neutral with regard to jurisdictional claims in published maps and institutional affiliations.

Copyright: (C) 2022 by the authors. Licensee MDPI, Basel, Switzerland. This article is an open access article distributed under the terms and conditions of the Creative Commons Attribution (CC BY) license (https:/ / creativecommons.org/licenses/by/ $4.0 /)$.

\begin{abstract}
This study examines the kinetics of pyrolysis and oxidation of hydrochars through thermal analysis. Thermogravimetric analysis (TGA) and differential scanning calorimetry (DSC) techniques were used to investigate the decomposition profiles and develop two distributed activation energy models (DAEM) of hydrochars derived from the hydrothermal carbonization of grape seeds produced at different temperatures $\left(180,220\right.$, and $\left.250{ }^{\circ} \mathrm{C}\right)$. Data were collected at 1,3 , and $10^{\circ} \mathrm{C} / \mathrm{min}$ between 30 and $700{ }^{\circ} \mathrm{C}$. TGA data highlighted a decomposition profile similar to that of the raw biomass for hydrochars obtained at 180 and $220^{\circ} \mathrm{C}$ (with a clear distinction between oil, cellulosic, hemicellulosic, and lignin-like compounds), while presenting a more stable profile for the $250^{\circ} \mathrm{C}$ hydrochar. DSC showed a certain exothermic behavior during pyrolysis of hydrochars, an aspect also investigated through thermodynamic simulations in Aspen Plus. Regarding the DAEM, according to a Gaussian model, the severity of the treatment slightly affects kinetic parameters, with average activation energies between 193 and $220 \mathrm{~kJ} / \mathrm{mol}$. Meanwhile, the Miura-Maki model highlights the distributions of the activation energy and the pre-exponential factor during the decomposition.
\end{abstract}

Keywords: hydrothermal carbonization; modeling; kinetics; thermal analysis; Aspen Plus; biomass; hydrochar

\section{Introduction}

The global increase in energy demand, driven mainly by the growing global population, urbanization, and economic growth, is depleting the world's reserves of fossil fuels, already strained by their high consumption rate, heightening environmental concerns, resource depletion, and rising costs. To face the problem, different renewable energy sources have been investigated, like wind, solar, hydropower, geothermal, and biomass. Among the different biomasses, those deriving from waste or agricultural residues, agro-industrial, horticulture, and wood processing, are cheap and convenient [1,2]. Besides, the use and valorizing of waste biomass are part of a circular economy context, where residues become the input for a new process [3]. At present, most of the waste produced in Europe is disposed of without any further treatment resulting in wastefulness of energy and resources and in serious environmental impact. A high-efficient use of waste not only increases its economic value but also results in environmental benefits [4].

In the last decades, biomass waste treatment and management have seen an increasing interest from the research community. Currently, biomass waste has characteristics that limit its use, including a low heating value, low fixed carbon content, high moisture content, low grindability, and non-uniformity. Studies on the conversion of biomass into high-quality biofuels have been performed to avoid the problems caused by direct combustion and find more effective methods of utilization, such as pyrolysis, gasification, torrefaction, and hydrothermal carbonization $[5,6]$. 
Despite pyrolysis, gasification, and torrefaction processes reducing moisture content and increasing fixed carbon content and heating value, all of them have a problem concerning high energy consumption and high pollutant emissions [6,7].

Hydrothermal carbonization (HTC) is a promising technique that can turn lignocellulose biomass into carbon-rich, solid, lignite-like fuel.

HTC is a thermochemical treatment able to recover energy from biomass wastes and eliminate organic contaminants and pollutants [8]. Similar to the natural coalification process, HTC lowers both the oxygen and hydrogen content of the feedstock, obtaining a final coal-like product referred to as hydrochar [9]. The process consists of subjecting the feedstock to mild temperatures $\left(180-250^{\circ} \mathrm{C}\right)$ and autogenous pressure in liquid water, ensuring a wide range of applicability for substrates with high moisture, up to $95 \mathrm{wt} . \%$ [10]. Hydrochar is endowed with higher calorific value and higher fixed carbon content compared to its precursor biomass [11]. Due to its potential, HTC is a mindful tool to treat biomass waste, recover materials, and provide an energy source. Hydrochar can be used as solid fuel and integrating HTC with other processes (like gasification, pyrolysis, anaerobic digestion [12], and composting [13]) can face shortcomings related to the single-stage, and improve the overall process efficiency. For example, HTC as a pre-treatment can affect the pyrolysis performance [1]. This last factor is important to control because it is the primary stage during the combustion and gasification processes (in view of using hydrochar as a fuel) and because it is a standalone process to produce biofuels (i.e., char, oil, syngas). In this framework, HTC can be used for the pre-conditioning of high moisture content biomass, making it hydrophobic (and thus allowing for a much cheaper dewatering/drying [2]), and then the biomass can undergo the dry pyrolysis treatment [14]. How much HTC could affect the pyrolysis rate depends on the type of feedstock involved $[15,16]$.

In this context, understanding the kinetics of pyrolysis and oxidation of hydrochar could help in designing a thermochemical conversion process.

Even though the application of hydrochar is important in boilers and burners, the kinetics and combustion performance of hydrochar have been poorly studied. Sharma et al. [17] showed that adding hydrochar to pulverized coal helps to decrease pollutant gas emissions. Moreover, the study of process kinetics and the modeling of its control in the industrial field is weak. Different models (e.g., the Kissinger-Akahira-Sunose method and the Coats-Redfern method) have also been adopted to investigate the combustion kinetics of hydrochar $[18,19]$, but the results obtained did not lead to quantitative data that fit well with the experimental values. Due to the importance of the kinetic behavior of hydrochar combustion, additional studies are needed. Actually, the distributed activation energy model (DAEM) is the most comprehensive model to investigate the thermal reaction kinetics of biomass. Bach et al. [20] employed DAEM to study the kinetic performance of combustion of wet-towered forest residues, while Chen et al. [6] applied DAEM to study the kinetic performance of pyrolysis of five lignocellulosic biomasses. Still, Zhang et al. [21] used a multi-Gaussian DAEM to investigate the decomposition characteristics of cellulose, hemicellulose, and lignin in different atmospheres. Therefore, the DAEM offers a higher quality of fit to the experimental data and can provide more information about the kinetics of biomass pyrolysis. DAEM was proposed originally by Vand [22] to model coal pyrolysis and is based on the hypothesis that the decomposition occurs through an infinite number of parallel reactions characterized by a certain distribution of activation energy. The energy distribution is often modeled through a continuous function, like the Gaussian, Weibull, or Boltzmann function [23]. Despite the diffusion of DAEMs to predict kinetics parameters of biomass and coal pyrolysis and oxidation [24-28], studies on the hydrochars are still very rare in the literature [20]. Therefore, this study used thermogravimetric analysis (TGA) to investigate the pyrolytic and oxidative behavior of hydrochars derived from an agro-industrial residue (grape seeds [29]).

In particular, TGA is a technique commonly adopted to analyze and examine biomass degradation in oxidation or pyrolysis patterns, and can be used to deduce kinetics parameters and mechanisms [30,31]. TGA data under inert and oxidative atmosphere were 
collected and used to determine kinetic parameters through two DAEMs (Gaussian and Miura-Maki DAEM). To do this, TGA data at different heating rates were collected, and activation energies and pre-exponential factors were computed. Analyses were also performed on the raw biomass and the oil contained inside the seeds. To investigate more in-depth the decomposition, derivative conversion curves were deduced, and the heat involved during the pyrolysis or oxidation was determined through differential scanning calorimetry (DSC). A simple thermodynamic model was also developed in Aspen Plus to compare experimental outputs with thermodynamic predictions. Through the software, pyrolysis and oxidation of the hydrochars were simulated and the outputs were compared with experimental measures from DSC to understand if this modeling approach can be used as a preliminary study of the heat of reactions.

\section{Materials and Methods}

\subsection{Starting Samples: Grape Seeds and Hydrochars}

The starting substrate consists of grape seeds and their corresponding hydrochars produced and characterized in previous work by our group [32]. Grape seeds are a residue of the winemaking industry and were provided by an alcohol producer company in the North of Italy (province of Trento). Hydrochars were obtained at 180, 220, and $250{ }^{\circ} \mathrm{C}$ through a solar HTC reactor, at a residence time of two hours, and a dry biomass to water weight ratio $(\mathrm{B} / \mathrm{W})$ of 0.3 [32]. Table 1 summarizes the main properties of the samples.

Table 1. Grape seeds and hydrochar (HC) properties, from the literature [32] (C: carbon, H: hydrogen, O: oxygen, N: nitrogen, S: sulfur, HHV: higher heating value).

\begin{tabular}{cccccccc}
\hline Sample & & \multicolumn{3}{c}{ Ultimate Analysis (wt.\%) } & \multicolumn{2}{c}{ HHV } \\
& $\mathbf{C}$ & $\mathbf{H}$ & $\mathbf{O}$ & $\mathbf{N}$ & $\mathbf{S}$ & Ash (wt.\%) & (MJ/kg) \\
\hline Grape seeds & 53.2 & 6.7 & 36.2 & 1.7 & 0.3 & 1.9 & 22.5 \\
HC $180^{\circ} \mathrm{C}$ & 59.7 & 6.7 & 29.4 & 1.5 & 0.4 & 2.3 & 24.9 \\
HC $220^{\circ} \mathrm{C}$ & 64.0 & 6.4 & 25.3 & 1.7 & 0.4 & 2.2 & 27.2 \\
HC $250^{\circ} \mathrm{C}$ & 69.2 & 6.5 & 19.4 & 2.0 & 0.3 & 2.5 & 30.5 \\
\hline
\end{tabular}

\subsection{Sample Characterization}

Grape seeds and hydrochars were characterized through thermogravimetric analysis (TGA), differential scanning calorimetry (DSC), and Fourier-transform infrared spectroscopy (FTIR).

TGA was performed in a thermobalance Mettler TG50 under non-isothermal conditions. $15 \mathrm{mg}$ of whole dried samples (i.e., the entire raw and carbonized grape seeds) were placed into a $70 \mu \mathrm{L}$ alumina crucible. Runs were performed between 40 and $700{ }^{\circ} \mathrm{C}$ at a heating rate of 1,3 , and $10^{\circ} \mathrm{C} / \mathrm{min}$, under $100 \mathrm{~mL} / \mathrm{min}$ of nitrogen or air $\left(20.95 \% \mathrm{O}_{2}\right.$ and $78.08 \% \mathrm{~N}_{2}$ ). The thermobalance has a sensitivity of $\pm 1 \times 10^{-3} \mathrm{mg}$ and $0.1^{\circ} \mathrm{C}$. The extent of conversion $\alpha$ at any time $t$ was computed as:

$$
\alpha(\mathrm{t})=\frac{\mathrm{m}_{0}-\mathrm{m}(\mathrm{t})}{\mathrm{m}_{0}-\mathrm{m}_{\mathrm{f}}}=\frac{\mathrm{v}(\mathrm{t})}{\mathrm{v}_{\infty}}
$$

where $m_{0}, m(t)$, and $m_{f}$ are the mass at time zero (dry), at a given time $t$, and final time, respectively. This corresponds to the ratio between $v(t)$, which represents the amount of volatiles evolved up to a certain time $t$, and $v_{\infty}$, which represents the amount of volatiles that evolved up to the end of the process.

DSC was performed in a Mettler DSC20 calorimeter between 40 and $600{ }^{\circ} \mathrm{C}$, at a heating rate of $10^{\circ} \mathrm{C} / \mathrm{min}$, under nitrogen or air at a flow rate of $100 \mathrm{~mL} / \mathrm{min}$. About $15 \mathrm{mg}$ of material was placed into a $40 \mu \mathrm{L}$ aluminum crucible. The heat released/absorbed was computed by integrating the measured heat flow over time in the $40-600{ }^{\circ} \mathrm{C}$ range, while the sample mass variation was recorded after every run. 
FTIR spectra of samples were acquired using PerkinElmer FT-IR spectrometer Spectrum One. Spectra were obtained over a wavenumber range of $4000-650 \mathrm{~cm}^{-1}$. Dried samples were ground to be compacted into a thin film and a flat top-plate Zinc Selenide crystal was used for the detection.

\subsection{Distributed Activation Energy Models (DAEMs)}

Two types of DAEMs (the Gaussian and the Miura-Maki [33]) were developed in software codes to model the decomposition of hydrochars, grape seeds, and grape seed oil.

In particular, when a first-order reaction is assumed to model biomass degradation, the variation of $\alpha$ vs. time can be expressed as the product between the reaction rate $\mathrm{k}$ and the conversion function $\mathrm{f}$ :

$$
\frac{\mathrm{d} \alpha}{\mathrm{dt}}=\mathrm{k}(\mathrm{T}) \mathrm{f}(\alpha)
$$

By adopting the Arrhenius theory, $\mathrm{k}(\mathrm{T})$ can be expressed by Equation (3):

$$
\mathrm{k}(\mathrm{T})=\mathrm{k}_{0} \exp \left(-\frac{\mathrm{E}}{\mathrm{RT}}\right)
$$

where $\mathrm{k}_{0}$ represents the pre-exponential factor, $\mathrm{E}$ is the activation energy, and $\mathrm{R}$ is the universal gas constant.

To deduce the kinetic parameters, $f(\alpha)$ is usually assumed in advance (in the so called model-fitting methods) and then forced to fit experimental data [23]. In particular, nonisothermal models usually adopt a constant heating rate $\beta$ equal to $\mathrm{dT} / \mathrm{dt}$, allowing the re-arrangement of Equation (3) into (4), which can be solved using thermogravimetric data [23].

$$
\frac{\mathrm{d} \alpha}{\mathrm{dT}} \cong \frac{\mathrm{d} \alpha}{\mathrm{dt}} \frac{\mathrm{dt}}{\mathrm{dT}}=\frac{\mathrm{d} \alpha}{\mathrm{dt}} \frac{1}{\beta}=\frac{\mathrm{k}(\mathrm{T})}{\beta} \mathrm{f}(\alpha)=\frac{\mathrm{k}_{0}}{\beta} \exp \left(-\frac{\mathrm{E}}{\mathrm{RT}}\right) \mathrm{f}(\alpha)
$$

Among model-fitting methods, DAEM assumes that pyrolysis can be described through an infinite number of irreversible first-order parallel reactions, with different rate parameters, which occur simultaneously [23,34]. In particular, the DAEM for a reaction order equal to 1 can be obtained by re-arranging Equations (2)-(4) as:

$$
1-\alpha=\int_{0}^{\infty} \exp \left(-\int_{\mathrm{T}_{0}}^{\mathrm{T}} \frac{\mathrm{k}_{0}}{\beta} \exp \left(-\frac{\mathrm{E}}{\mathrm{RT}}\right) \mathrm{dT}\right) \mathrm{f}(\mathrm{E}) \mathrm{dE}
$$

Equation (5) does not have an analytical solution and there are two families of methods to solve it. One is referred to as distribution-fitting method and the other as isoconversional methods. The distribution-fitting method assumes $\mathrm{f}(\mathrm{E})$ (like a Gaussian, Weibull, or Boltzmann distribution) and forces to fit the TGA data by applying a certain numerical method [23]. Meanwhile, isoconversional methods do not assume $f(\alpha)$, but adopt a series of thermogravimetric data at different heating rates to directly compute the activation energy. The reaction rate at a certain $\alpha$ is a function of temperature. Among these distribution-free methods, the Miura-Maki integral method is a common one [35].

\subsubsection{Gaussian Model}

In the Gaussian DAEM, the distribution function $\mathrm{f}(\mathrm{E})$ is assumed to be a Gaussian distribution with mean activation energy $\mathrm{E}_{0}$ and standard deviation $\sigma$, which is:

$$
f(E)=\frac{1}{\sigma \sqrt{2 \pi}} \exp \frac{\left(E-E_{0}\right)^{2}}{2 \sigma^{2}}
$$


Applying the Coats-Redfern [36] and Fisher et al. [37] approximations, Equation (7) is obtained.

$$
1-\alpha=\int_{0}^{\infty}\left(\exp \left(-\frac{\mathrm{k}_{0} \mathrm{RT}^{2}}{\beta \mathrm{E}} \exp \left(-\frac{\mathrm{E}}{\mathrm{RT}}\right)\right)\right) \frac{1}{\sigma \sqrt{2 \pi}} \exp \frac{\left(\mathrm{E}-\mathrm{E}_{0}\right)^{2}}{2 \sigma^{2}} \mathrm{dE}
$$

To solve Equation (7), the authors applied the simplification reported by Anthony and Howard [38], which consists in keeping $\mathrm{k}_{0}$ constant and equal to $1.67 \times 10^{13} \mathrm{~s}^{-1}$, and the minimization procedure proposed by Güneş and Güneş [39] that solves the integral using the Simpson's 1/3 rule. To avoid oscillations in the results, $\mathrm{dE}$ was kept constant at $50 \mathrm{~kJ} / \mathrm{mol}$, while the extremes of integration were iteratively adjusted according to $E_{0}$. Then, the best solution was calculated by iterating the solution of the integral for several values of $\mathrm{E}_{0}$ and $\sigma$ and minimizing h, i.e., the root mean quadratic error between the model output and the experimental data:

$$
\mathrm{h}=\sqrt{\frac{\sum_{\mathrm{j}=1}^{\mathrm{n}}\left(\alpha_{\mathrm{TGA}, \mathrm{j}}-\alpha_{\mathrm{DAEM}, \mathrm{j}}\right)^{2}}{\mathrm{n}}}
$$

where $\alpha_{\mathrm{TGA}, \mathrm{j}}$ and $\alpha_{\mathrm{DAEM}, \mathrm{j}}$ are the experimental and calculated extent of conversion, respectively, and $n$ is the number of available data points.

The code was developed in MATLAB and a direct search technique was adopted [39]. The code is reported in Supplementary Materials. Firstly, a larger grid procedure was used for both $\mathrm{E}_{0}$ and $\sigma$, with a step size equal to 5 . The first three values minimizing $\mathrm{h}$ were obtained. Then, for these last three values, an iteration process using $\mathrm{E}_{0} \pm 5$ and $\sigma \pm 5$ with a step equal to 1 was set. Finally, final values were used to solve the integral of Equation (7) and to calculate $\alpha_{\text {DAEM }}$.

\subsubsection{Miura-Maki Model}

The Miura-Maki model adopts some assumptions to determine $\mathrm{f}(\mathrm{E})$ and $\mathrm{k}_{0}$ without any a priori assumption on the energy distribution [33]. In particular, Miura and Maki approximated $[33,35]$ the so called $\Phi$ function (Equation (9)) to a step-function $E=E_{S}$ for a selected temperature $\mathrm{T}$.

$$
\Phi(\mathrm{E}, \mathrm{T})=\exp \left(-\mathrm{k}_{0} \int_{0}^{\mathrm{t}} \exp \left(-\frac{\mathrm{E}}{\mathrm{RT}}\right) \mathrm{dt}\right) \cong \exp \left(-\frac{\mathrm{k}_{0}}{\beta} \int_{0}^{\mathrm{T}} \exp \left(-\frac{\mathrm{E}}{\mathrm{RT}}\right) \mathrm{dT}\right)
$$

Thus, Equation (5) can be written as:

$$
\alpha \cong 1-\int_{E_{s}}^{\infty} f(E) d E=\int_{0}^{E_{s}} f(E) d E
$$

with $\mathrm{E}_{\mathrm{s}}$ so that $\Phi\left(\mathrm{E}_{\mathrm{s}}, \mathrm{T}\right) \cong 0.58$.

By the Miura and Maki approach, only a reaction having an activation energy $E_{s}$ occurs at a given $\mathrm{T}$ and $\beta$-the model simplifies an actual reaction system by a set of $\mathrm{N}$ reactions, characterized by their own activation energy and pre-exponential factor.

Approximating the function $\Phi(\mathrm{E}, \mathrm{T})$ as:

$$
\Phi(\mathrm{E}, \mathrm{T}) \cong \exp \left(-\frac{\mathrm{k}_{0} \mathrm{RT}^{2}}{\beta \mathrm{E}} \exp \left(-\frac{\mathrm{E}}{\mathrm{RT}}\right)\right)
$$

the extent of conversion for the $j$-th reaction is expressed by Equation (12):

$$
1-\frac{\Delta \mathrm{v}}{\Delta \mathrm{v}_{\infty}} \cong \exp \left(-\frac{\mathrm{k}_{0} \mathrm{RT}^{2}}{\beta \mathrm{E}} \exp \left(-\frac{\mathrm{E}}{\mathrm{RT}}\right)\right)
$$


where $\Delta \mathrm{v}$ and $\Delta \mathrm{v}_{\infty}$ represent the amount of volatiles evolved and the effective volatile content for the j-th reaction.

After some mathematical steps [35], and after imposing $1-\Delta \mathrm{v} /\left(\Delta \mathrm{v}_{\infty}\right)=\Phi(\mathrm{E}, \mathrm{T}) \cong$ 0.58 , the representative equation of the Miura-Maki model is given by Equation (13).

$$
\ln \left(\frac{\beta}{\mathrm{T}^{2}}\right)=\ln \left(\frac{\mathrm{k}_{0} \mathrm{R}}{\mathrm{E}}\right)+0.6075-\frac{\mathrm{E}}{\mathrm{RT}}
$$

Compared to the Gaussian DAEM, the approach of Miura [35] and Miura and Maki [33] relies on the dependence of $\mathrm{k}_{0}$ on $\mathrm{E}$. In particular, they proposed a simple procedure to estimate $f(E)$ and $k_{0}$, consisting of the following steps:

(1) measurement of $\alpha$ vs. T relationship for at least three heating rates;

(2) calculation of $\beta / \mathrm{T}^{2}$ at selected $\alpha$ values from the $\alpha$ vs. T relationship obtained in (1) for each heating rate;

(3) plotting of $\ln \left(\beta / \mathrm{T}^{2}\right)$ vs. $-1 /(\mathrm{RT})$ at the selected $\alpha$ values, and determination of $\mathrm{E}$ and $\mathrm{k}_{0}$ from the Arrhenius plot at different $\alpha$ values using the relationship represented by Equation (13): E can be estimated by the slope, and $k_{0}$ by the intercept of each line with the y axis; and

(4) plotting the $\alpha$ value against the activation energy $E$, as calculated in (3), and differentiating the $\alpha$ vs. E relationship to obtain $\mathrm{f}(\mathrm{E})$.

\subsection{Aspen Plus Model}

The energy aspects of pyrolysis were thermodynamically investigated by performing some Aspen Plus simulations reproducing the pyrolysis of hydrochars. The model is based on thermodynamic equilibrium and the minimization of the Gibbs energy, without considering any kinetic phenomena. In particular, the thermodynamic properties of the conventional components were calculated by adopting the Peng-Robinson method.

Simulations were performed on grape seeds, hydrochars, and a commercial coal. Table 2 reports a summary of all input data, while Figure 1 shows the general Aspen scheme. The stream REACTANT represents the input feedstock entering the process, defined through a non-conventional stream characterized by its ultimate analysis and HHV (grape seeds and hydrochar in Table 1, coal Illinois No. 6 from literature [40]). Then, the RYIELD reactor, which is fictitious, splits the non-conventional stream into a conventional one (ELEMENTS) based on its elemental distribution. This stream enters the RGIBBS reactor, which computes the product distribution as a function of the operating conditions (i.e., temperature and pressure) by minimizing the Gibbs energy of the product mixture. The final products considered in the model are carbon graphite, carbon dioxide $\left(\mathrm{CO}_{2}\right)$, carbon monoxide $(\mathrm{CO})$, water $\left(\mathrm{H}_{2} \mathrm{O}\right)$, hydrogen $\left(\mathrm{H}_{2}\right)$, oxygen $\left(\mathrm{O}_{2}\right)$, methane $\left(\mathrm{CH}_{4}\right)$, acetylene $\left(\mathrm{C}_{2} \mathrm{H}_{2}\right)$, ethylene $\left(\mathrm{C}_{2} \mathrm{H}_{4}\right)$, and ethane $\left(\mathrm{C}_{2} \mathrm{H}_{6}\right)$, to ensure a good model performance. Then, the net heat required/produced by the process is given by stream QOUT, while QIN represents the heat required to sustain RYIELD. Runs were performed between 300 and $900{ }^{\circ} \mathrm{C}$ (every block and stream were kept isotherm to avoid any sensible heat contribution) to deduce the amount of heat involved during the reaction. The product distribution at different temperatures was also investigated. Data were referred per gram of dry feedstock entering the process.

Table 2. Summary of parameters used in the Aspen Plus simulations.

$\begin{array}{ll}\text { Feedstock } & \text { Grape seeds, } \mathrm{HC} 180{ }^{\circ} \mathrm{C}, \mathrm{HC} 220^{\circ} \mathrm{C}, \mathrm{HC} 250{ }^{\circ} \mathrm{C}, \mathrm{Coal} \\ \text { Products (at equilibrium) } & \mathrm{C} \text { (graphite), } \mathrm{CO}_{2}, \mathrm{CO}, \mathrm{H}_{2}, \mathrm{O}_{2}, \mathrm{H}_{2} \mathrm{O}, \mathrm{CH}_{4}, \mathrm{C}_{2} \mathrm{H}_{2}, \mathrm{C}_{2} \mathrm{H}_{4}, \mathrm{C}_{2} \mathrm{H}_{6} \\ \begin{array}{l}\text { Equation of state } \\ \text { Pyrolysis temperature }\end{array} & \text { Peng-Robinson } \\ & 300-900{ }^{\circ} \mathrm{C}\end{array}$




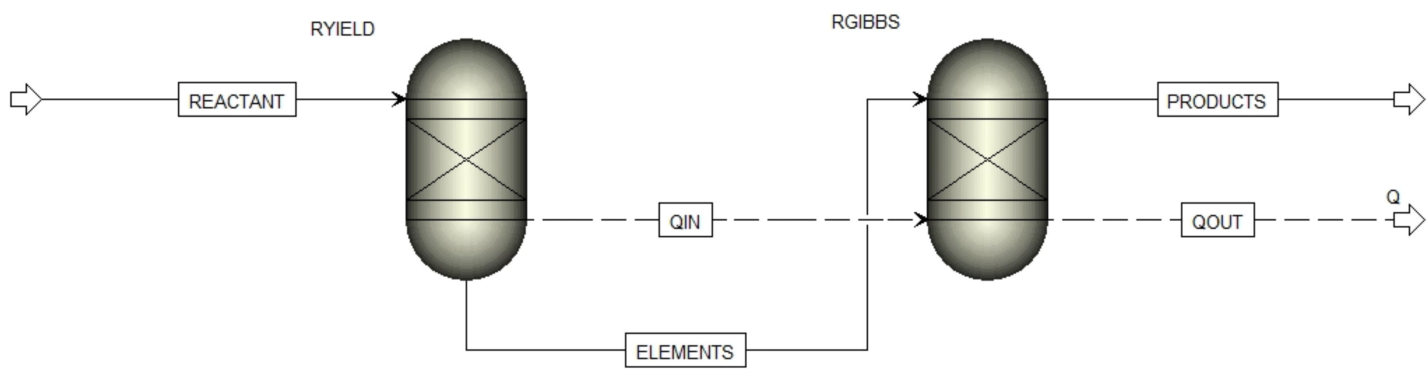

Figure 1. Aspen Plus scheme used to model pyrolysis.

\section{Results and Discussion}

\subsection{Derivative Thermogravimetric Curves}

Figure 2 shows the derivative thermogravimetric curves (DTGA) of grape seeds and hydrochars under pyrolytic and oxidative conditions, at different heating rates. Table 3 shows a sum of the position of local peaks, with their temperatures and intensities.

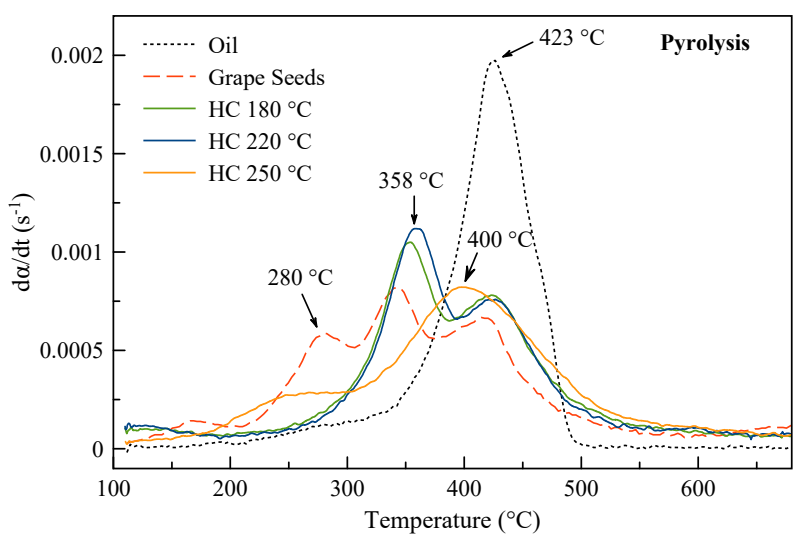

(a)

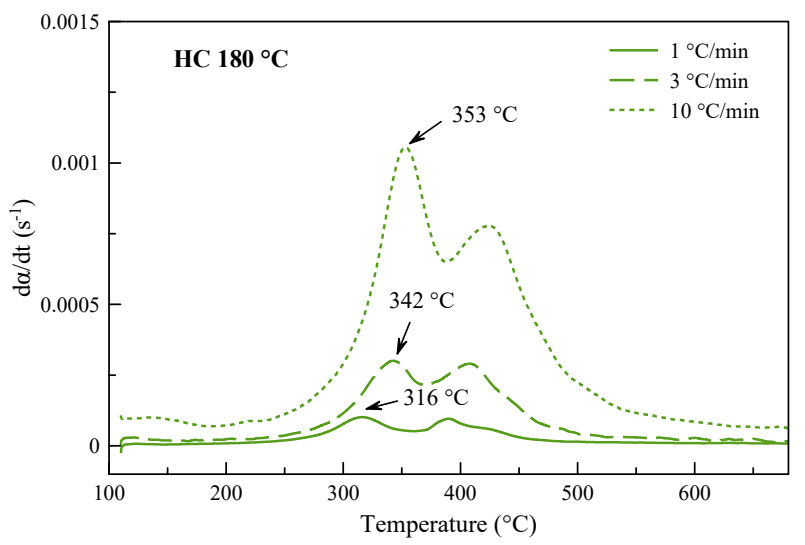

(c)

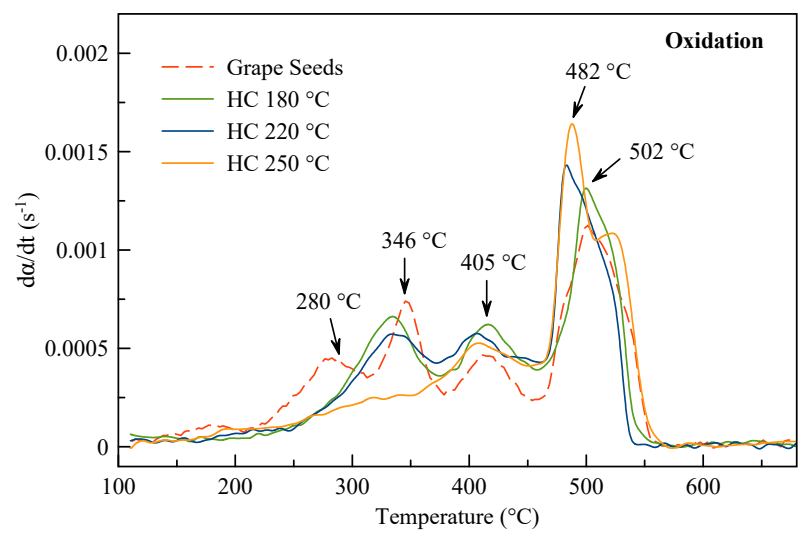

(b)

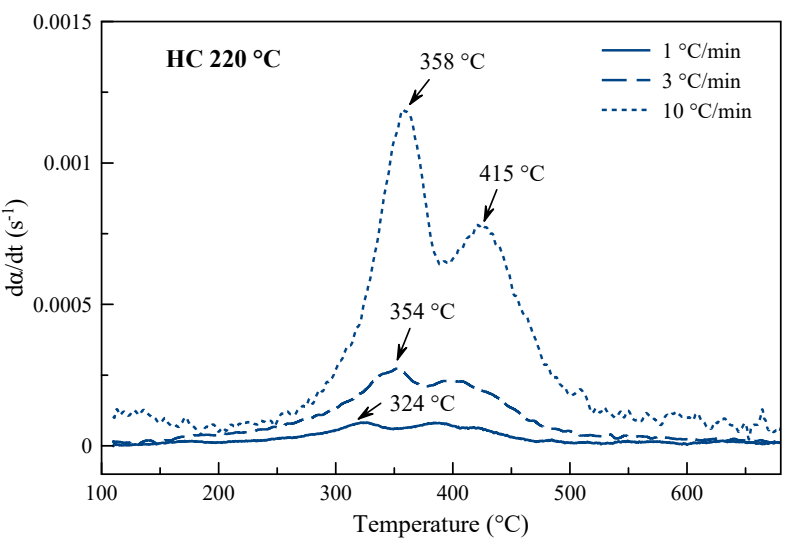

(d)

Figure 2. Cont. 


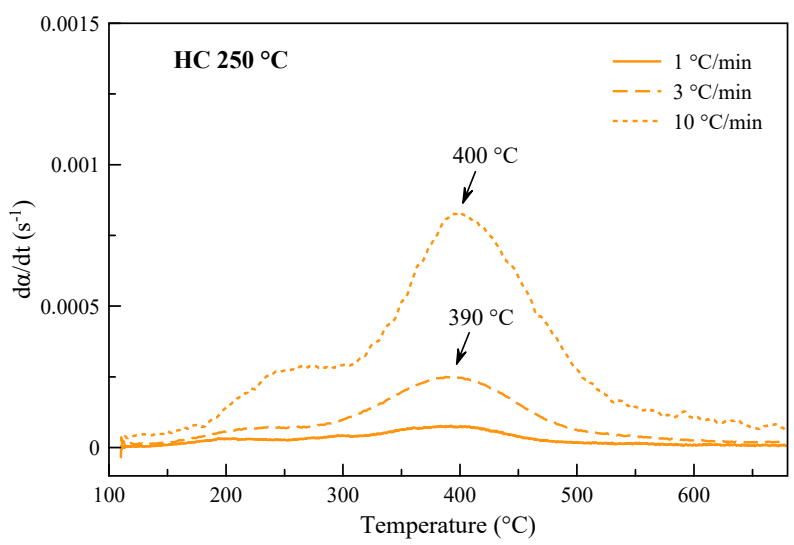

(e)

Figure 2. Derivative thermogravimetric (DTGA) curves: (a) during pyrolysis at $10^{\circ} \mathrm{C} / \mathrm{min}$; (b) during oxidation at $10^{\circ} \mathrm{C} / \mathrm{min}$; (c) effect of the heating rate during pyrolysis of hydrochar $180{ }^{\circ} \mathrm{C}$; (d) effect of the heating rate during pyrolysis of hydrochar $220^{\circ} \mathrm{C}$; (e) effect of the heating rate during pyrolysis of hydrochar $250^{\circ} \mathrm{C}$. HC: hydrochars, $\mathrm{d} \alpha / \mathrm{dt}$ : derivative conversion curve of the extent of conversion $\alpha$ with respect to time $t$.

Table 3. DTGA peak temperature and decomposition rate of pyrolysis and oxidation $\left(10^{\circ} \mathrm{C} / \mathrm{min}\right)$.

\begin{tabular}{|c|c|c|c|c|c|c|c|c|c|c|}
\hline \multirow{2}{*}{\multicolumn{2}{|c|}{ DTGA Peak }} & \multicolumn{5}{|c|}{ Pyrolysis } & \multicolumn{4}{|c|}{ Oxidation } \\
\hline & & Oil & $\begin{array}{l}\text { Grape } \\
\text { Seeds }\end{array}$ & $\begin{array}{c}\mathrm{HC} \\
180^{\circ} \mathrm{C}\end{array}$ & $\begin{array}{c}\mathrm{HC} \\
220^{\circ} \mathrm{C}\end{array}$ & $\begin{array}{c}\mathrm{HC} \\
250^{\circ} \mathrm{C}\end{array}$ & $\begin{array}{l}\text { Grape } \\
\text { Seeds }\end{array}$ & $\begin{array}{c}\mathrm{HC} \\
180^{\circ} \mathrm{C}\end{array}$ & $\begin{array}{c}\mathrm{HC} \\
220^{\circ} \mathrm{C}\end{array}$ & $\begin{array}{c}\mathrm{HC} \\
250^{\circ} \mathrm{C}\end{array}$ \\
\hline \multirow[b]{2}{*}{1} & $\mathrm{~T}\left({ }^{\circ} \mathrm{C}\right)$ & - & 280 & - & - & - & 280 & - & - & - \\
\hline & $\begin{array}{c}\mathrm{d} \alpha / \mathrm{dt} \\
\left(\mathrm{s}^{-1}\right)\end{array}$ & - & $5.9 \times 10^{-4}$ & - & - & - & $4.4 \times 10^{-4}$ & - & - & - \\
\hline \multirow[b]{2}{*}{2} & $\mathrm{~T}\left({ }^{\circ} \mathrm{C}\right)$ & - & 343 & 353 & 358 & - & 346 & 334 & 336 & - \\
\hline & $\begin{array}{c}\mathrm{d} \alpha / \mathrm{dt} \\
\left(\mathrm{s}^{-1}\right)\end{array}$ & - & $8.2 \times 10^{-4}$ & $1.0 \times 10^{-3}$ & $1.1 \times 10^{-3}$ & - & $7.4 \times 10^{-4}$ & $6.6 \times 10^{-4}$ & $5.7 \times 10^{-4}$ & - \\
\hline \multirow[b]{2}{*}{3} & $\mathrm{~T}\left({ }^{\circ} \mathrm{C}\right)$ & 423 & 421 & 424 & 428 & 400 & 415 & 415 & 406 & 409 \\
\hline & $\begin{array}{c}\mathrm{d} \alpha / \mathrm{dt} \\
\left(\mathrm{s}^{-1}\right)\end{array}$ & $2.0 \times 10^{-3}$ & $6.6 \times 10^{-4}$ & $7.8 \times 10^{-4}$ & $7.7 \times 10^{-4}$ & $8.2 \times 10^{-4}$ & $4.6 \times 10^{-4}$ & $6.2 \times 10^{-4}$ & $5.8 \times 10^{-4}$ & $5.3 \times 10^{-4}$ \\
\hline \multirow[b]{2}{*}{4} & $\mathrm{~T}\left({ }^{\circ} \mathrm{C}\right)$ & - & - & - & - & - & 502 & 502 & 482 & $480-523$ \\
\hline & $\begin{array}{c}\mathrm{d} \alpha / \mathrm{dt} \\
\left(\mathrm{s}^{-1}\right)\end{array}$ & - & - & - & - & - & $1.1 \times 10^{-3}$ & $1.3 \times 10^{-3}$ & $1.4 \times 10^{-3}$ & $1.6-1.1 \times 10^{-3}$ \\
\hline
\end{tabular}

Overall, both grape seeds and hydrochars mostly decompose between 200 and $500{ }^{\circ} \mathrm{C}$, indicating that most of the volatile matter is removed in this range. Grape seeds present three main decomposition peaks, occurring at 280,343 , and $421{ }^{\circ} \mathrm{C}$ under a pyrolytic atmosphere. These peaks can be attributed to the overlapped decomposition of hemicellulose, lignin plus cellulose, and oil, which are the main constituents of grape seeds (around 7\% cellulose, $31 \%$ hemicellulose, $44 \%$ lignin, and $10-15 \%$ oil [41,42]). Indeed, it is well known that under pyrolytic conditions, due to its amorphous and little polymerized structure, hemicellulose is very reactive at low temperatures (in the range of $250-300{ }^{\circ} \mathrm{C}[21,43]$ ). In the DTGA curves, this reactivity translates into the first decomposition peak. Meanwhile, the second peak can be attributed to the overlapped decomposition of lignin and cellulose, which both generally decompose in the $300-350{ }^{\circ} \mathrm{C}$ range [43]. Considering the low content of cellulose (around 7\% [41,42]), lignin clearly dominates at this temperature. Beyond this decomposition, lignin also contributes by forming a decomposition "baseline" to the profile, overlapping the other components. Indeed, due to its high polymerized structure and higher heterogeneity, it decomposes also (less intensively than at $300-350^{\circ} \mathrm{C}$ ) in a broad range of temperatures, from around $230^{\circ}$ up to $600^{\circ} \mathrm{C}$ [43]. Therefore, during the pyrolysis of grape seeds, its decomposition could overlap to that of the other constituents, forming a "baseline" to the overall profile. Meanwhile, comparing the measured curve with that of 
grape seed oil from previous work by our group [28], it is clear that the peak occurring at $423^{\circ} \mathrm{C}$ can be attributed to the decomposition of the oil. Regarding the hydrochars, through $\mathrm{HTC}$, grape seeds undergo carbonization, decreasing their atomic $\mathrm{O} / \mathrm{C}$ and $\mathrm{H} / \mathrm{C}$ ratios with a natural reduction of the volatile matter as the harshness of the process increases [32]. In DTGA curves, this translates in flattening the first decomposition peak at around $280{ }^{\circ} \mathrm{C}$, which is indeed absent for all the hydrochars. Therefore, the authors can affirm that hemicellulosic compounds are mostly degraded during HTC. Interestingly, the $250{ }^{\circ} \mathrm{C}$ hydrochar exhibits a broad and not intense decomposition between 200 and $300^{\circ} \mathrm{C}$. Since hemicellulose degrades during HTC, this reactivity can be explained by the presence of re-polymerized compounds from the aqueous phase. Indeed, during HTC, sugar-derived compounds dissolved in the aqueous phase (like 5-HMF) can undergo condensation and re-polymerization, forming a solid phase called "secondary char" [44]. Beyond this, fatty acids formed during the hydrolysis of the oil could also be embedded in the solid phase, conferring to the sample an extra-reactivity at low temperatures. Both grape seeds and 180 and $220^{\circ} \mathrm{C}$ hydrochars show their highest reactivity at around $350{ }^{\circ} \mathrm{C}$, attributable to the degradation of lignin and cellulosic derived compounds. Differences can be due to both the heterogeneity of the feedstock and the synergistic behavior among the constituents, which are present in different ratios in the various samples. Conversely, the $250{ }^{\circ} \mathrm{C}$ hydrochar, after the initial slow decomposition at $200-300{ }^{\circ} \mathrm{C}$, shows only one main decomposition peak at $400{ }^{\circ} \mathrm{C}$. Therefore, while the 180 and $220^{\circ} \mathrm{C}$ hydrochars tend to follow the feedstock profile (2nd and 3 rd peaks), the $250^{\circ} \mathrm{C}$ hydrochar highly deviates from that, highlighting the impact of the HTC operating temperature on the devolatilization profile. Overall, it is important to highlight to positive effect of the HTC treatment: after HTC, curves tend to shift towards the right region of the graph, demonstrating a higher thermal stability during the degradation process.

Regarding oxidative conditions (Figure $2 b$ ), as expected by typical combustion profiles of biomass fuels [20], all the profiles can be divided into two regions: a first phase during which the feedstock devolatilizes to char, and a second phase where char oxidation occurs. The first phase, between 250 and $450{ }^{\circ} \mathrm{C}$, resembles the pyrolytic behavior: hemicellulose, lignin plus cellulose, and oil volatilize in the same temperature ranges as during pyrolysis. Then, the second phase, $480-520^{\circ} \mathrm{C}$, corresponds to the oxidation of the char formed during the first phase. This phase is predominant with respect to the previous phase. As for pyrolysis, the 180 and $220^{\circ} \mathrm{C}$ hydrochars resemble the behavior of grape seeds, exhibiting three main DTGA peaks. Meanwhile, the $250^{\circ} \mathrm{C}$ hydrochar presents only two DTGA peaks, demonstrating the harshness of severe HTC conditions on the feedstock structure and composition. Oxidation and pyrolysis TGA curves where (1- $\alpha)$ is plotted vs. T are reported in Supplementary Materials Figure S1.

Figure $2 c-e$ show the effect of the heating rate on DTGA curves. The heating rate does not affect the shape of the decomposition profile. Meanwhile, the DTGA peak moves towards higher temperatures at increasing heating rates, which can be due to heat and mass transfer phenomena and intrinsic devolatilization kinetics. Indeed, at higher rates, the mismatch between the temperature in the furnace and the particle is higher, and therefore there is a delay between the temperature measured and the decomposition stage [45]. In addition, the $\mathrm{d} \alpha / \mathrm{dt}$ is higher at higher rates because, at a fixed $\alpha, \mathrm{dt}$ is smaller. In addition, higher rates cause a bigger gradient between the surface and core temperature of the sample [45].

\subsection{DSC Curves}

Figure 3 shows DSC curves under nitrogen and oxidative atmosphere. Under an inert atmosphere, both grape seeds and hydrochars show an initial endothermic phase followed by an exothermic one at higher temperatures. The transition from an endoto an exothermic behavior occurs in a temperature range between 200 and $290{ }^{\circ} \mathrm{C}$. The heat request comprises both the heat necessary to evaporate water and that to trigger endothermic reactions. Water derives from both some residual moisture and some produced 
during condensation reactions occurring at the beginning of pyrolysis. Meanwhile, after the transition temperature, heat is released during pyrolysis. This behavior was already observed in literature with hydrochars derived from other feedstock $[40,46]$ and can be attributed to the presence of non-oxidized oxygen on the hydrochar, like in the form of carboxylic groups. Indeed, this oxygen is enough to oxidize the elemental carbon, leading to a heat release. As shown in Table 4, the net energy balance along the temperature spectrum $40-600{ }^{\circ} \mathrm{C}$ is positive for all the samples, highlighting that overall pyrolysis releases thermal energy. Not surprisingly and consistently with elemental analysis (Table 1), a higher heat release is associated with a higher volatile matter loss (Table 4). Details on the progressive integration of DSC data are given later in the paper (namely, in Section 3.5).

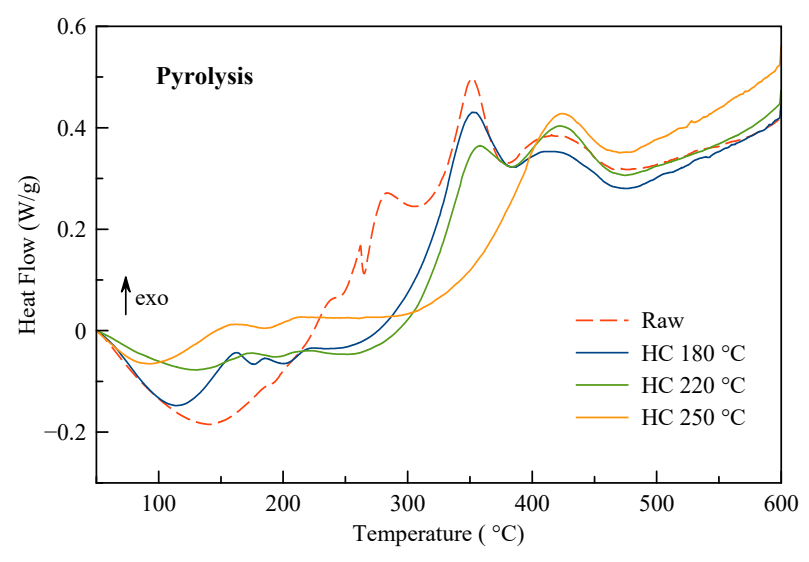

(a)

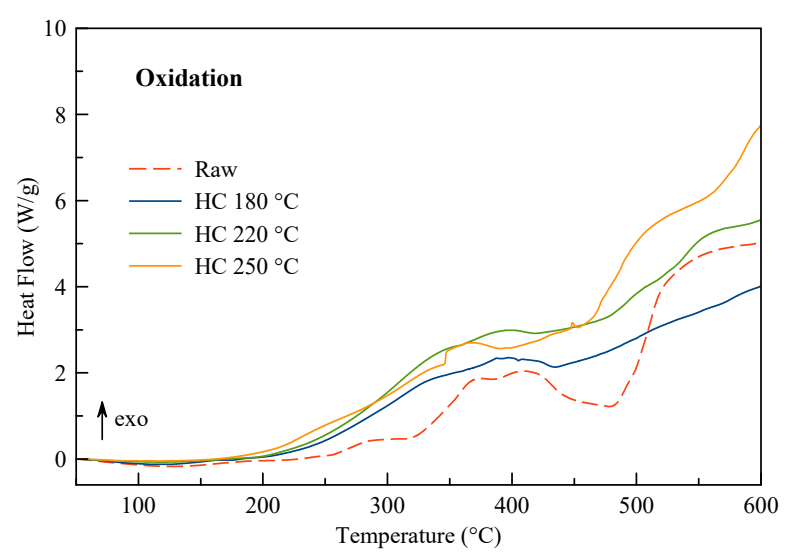

(b)

Figure 3. Differential scanning calorimetry (DSC) curves of grape seeds and hydrochars (HC) at $10{ }^{\circ} \mathrm{C} / \mathrm{min}$ : (a) under inert and (b) oxidative atmosphere ( $>0$ exothermic, $<0$ endothermic); per grams of dry feedstock.

Table 4. Details of DSC curves: integrals, mass loss, and transition point from endothermic to exothermic behavior; per kilograms of dry feedstock. The positive values of "Net energy" correspond to exothermal behavior during thermal treatments.

\begin{tabular}{|c|c|c|c|c|c|c|c|c|}
\hline & \multicolumn{4}{|c|}{ Pyrolysis } & \multicolumn{4}{|c|}{ Oxidation } \\
\hline & Raw & $\mathrm{HC} 180^{\circ} \mathrm{C}$ & $\mathrm{HC} 220^{\circ} \mathrm{C}$ & $\mathrm{HC} 250^{\circ} \mathrm{C}$ & Raw & $\mathrm{HC} 180^{\circ} \mathrm{C}$ & $\mathrm{HC} 220^{\circ} \mathrm{C}$ & HC $250{ }^{\circ} \mathrm{C}$ \\
\hline $\begin{array}{l}\text { Endothermic }{ }^{1} \\
(\mathrm{~J} / \mathrm{g})\end{array}$ & 118 & 90 & 67 & 23 & 98 & 54 & 31 & 19 \\
\hline Exothermic $^{1}(\mathrm{~J} / \mathrm{g})$ & 705 & 587 & 585 & 598 & 4406 & 4928 & 6678 & 7533 \\
\hline Net energy $^{1}(\mathrm{~J} / \mathrm{g})$ & 587 & 497 & 518 & 575 & 4309 & 4874 & 6647 & 7514 \\
\hline Mass loss ${ }^{1}(\%)$ & 61.2 & 56.2 & 55.4 & 43.7 & 73.7 & 69.0 & 73.3 & 69.0 \\
\hline
\end{tabular}

${ }^{1}$ Integral and mass losses computed/measured in the range $40-600{ }^{\circ} \mathrm{C}$.

As for DTGA curves, samples show heat profiles with local peaks. Indeed, grape seeds show three main peaks, at 280,352 , and $410-425^{\circ} \mathrm{C}$, in correspondence with the degradation of hemicellulose, lignin plus cellulose, and oil. The 180 and $220^{\circ} \mathrm{C}$ hydrochars show two peaks, while the $250^{\circ} \mathrm{C}$ shows only one at $420^{\circ} \mathrm{C}$. A comparison between DTGA and DSC curves under pyrolytic atmosphere is reported in Supplementary Materials Figure S2.

As expected from the nature of the process, under oxidative conditions (Figure $3 b$ ), the amount of heat released increases as the carbonization degree of the sample increases. All the samples show a slight endothermic behavior at low temperature, justified by the absence or low presence of oxidative reactions at this condition. Overall, the heat release profile is broad and rises to the final observed temperature. Indeed, at $600^{\circ} \mathrm{C}$, a certain quantity of matter that undergoes oxidation is still present. Even if less sharp than under an inert atmosphere, all the samples show a peak at $350-450{ }^{\circ} \mathrm{C}$ that can be associated with 
the oxidation of lignin-like compounds. Grape seeds also show a small inflection at $280^{\circ} \mathrm{C}$, probably due to the oxidation of hemicellulosic compounds.

\subsection{FTIR}

Figure 4 reports the FTIR spectra of the samples. The deflection at $3300 \mathrm{~cm}^{-1}$ indicates the stretching of the hydroxyl group, occurring generally in the range $3700-3200 \mathrm{~cm}^{-1}$ [47]. Increasing HTC temperature results in a decreasing intensity in $\mathrm{O}-\mathrm{H}$ stretching, because dehydration phenomena occur during HTC treatment. The peak at $3010 \mathrm{~cm}^{-1}$ represents $=\mathrm{C}-\mathrm{H}$ group stretch, which tends to gradually disappear in the hydrochars. This fact can be related to double bonds present in the oil, which degrades, and it is even not present in HC $250{ }^{\circ} \mathrm{C}$. Purnomo et al. [48] identified hydrogen bonded to the unsaturated carbon chain $(\mathrm{C}-\mathrm{H})$, whereas peaks at lower wavelength represent attachment to the saturated carbon chain. The peak at $1744 \mathrm{~cm}^{-1}$ indicates a typical bending of carbonyl group $>\mathrm{C}=\mathrm{O}$, possibly in the form of aldehyde [5], and/or the ester group in glyceride compounds. It tends to attenuate by increasing HTC treatment severity. Whereas grape seeds and HC $180{ }^{\circ} \mathrm{C}$ still present a peak, the $\mathrm{HC} 220^{\circ} \mathrm{C}$ spectrum moves toward a lower wavelength. In the $\mathrm{HC} 250{ }^{\circ} \mathrm{C}$ spectrum the peak disappeared, confirming degradation and formation of new compounds during the hydrothermal treatment. Furthermore, Diaz et al. [41] state that peaks around $1030 \mathrm{~cm}^{-1}$ indicate $\mathrm{C}-\mathrm{O}$ and $\mathrm{C}-\mathrm{O}-\mathrm{C}$ stretching, confirming that both decarboxylation and dehydration occurred. The grape seed spectrum exhibits a shoulder at a wavelength equal to $1655 \mathrm{~cm}^{-1}$, attributed to stretching of double bond $>C=C<[47]$, that tends to flatten out in hydrochars. Unsaturated double-bound $>\mathrm{C}=\mathrm{C}<$ could be related to the presence of oil [6] - grape seed oil is mainly composed of linoleic acid [48,49], having two double bonds $\mathrm{C}=\mathrm{C}$ in position 9 and 12. In general, functional groups act a stretch toward the region at a shorter wavelength.

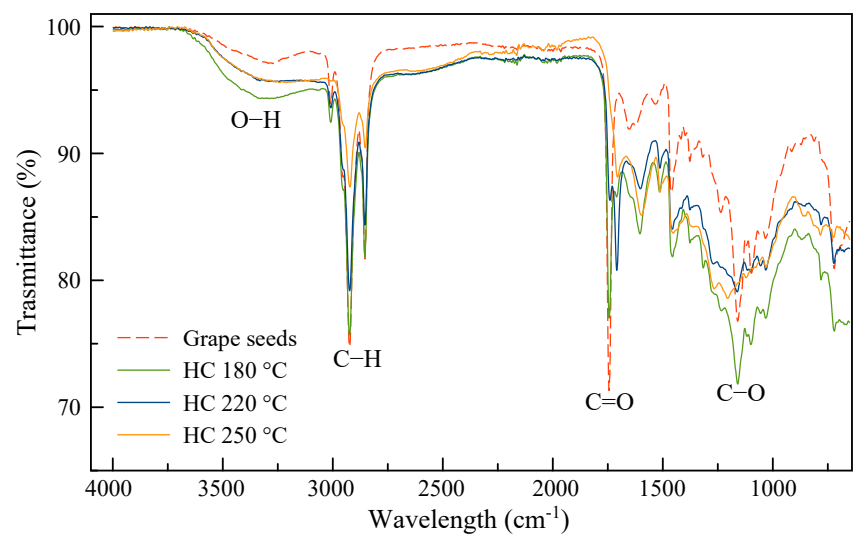

Figure 4. Fourier transform infrared spectroscopy (FTIR) curves of grape seeds and hydrochars (HC).

\subsection{Kinetic Models}

\subsubsection{Gaussian Model}

Table 5 shows $\mathrm{E}_{0}, \sigma$, and $\mathrm{h}$ computed through the Gaussian model at different heating rates for the various substrates, while Figure 5 shows the experimental data compared with the modeling curves for pyrolysis (data and curves relevant to oxidation are available in Supplementary Materials Figure S3). Experimental data are the starting point to compute DTGA curves reported in Figure 2. 
Table 5. Values of $E_{0}$ and $\sigma$ for the Gaussian model for the different substrates and heating rates; per moles of dry feedstock. $\mathrm{k}_{0}$ is let constant and equal to $1.67 \times 10^{13} \mathrm{~s}^{-1}$.

\begin{tabular}{|c|c|c|c|c|c|c|c|}
\hline & & & Grape Seeds & Oil & $\mathrm{HC} 180^{\circ} \mathrm{C}$ & $\mathrm{HC} 220^{\circ} \mathrm{C}$ & $\mathrm{HC} 250^{\circ} \mathrm{C}$ \\
\hline \multirow{9}{*}{ Pyrolysis } & \multirow{3}{*}{$\mathrm{E}_{0}(\mathrm{~kJ} / \mathrm{mol})$} & $1^{\circ} \mathrm{C} / \mathrm{min}$ & - & - & 205 & 207 & 209 \\
\hline & & $3{ }^{\circ} \mathrm{C} / \mathrm{min}$ & - & - & 203 & 202 & 206 \\
\hline & & $10^{\circ} \mathrm{C} / \mathrm{min}$ & 193 & 218 & 200 & 200 & 204 \\
\hline & \multirow{3}{*}{$\begin{array}{c}\sigma \\
(\mathrm{kJ} / \mathrm{mol})\end{array}$} & $1^{\circ} \mathrm{C} / \mathrm{min}$ & - & - & 15 & 16 & 17 \\
\hline & & $3{ }^{\circ} \mathrm{C} / \mathrm{min}$ & - & - & 14 & 15 & 16 \\
\hline & & $10^{\circ} \mathrm{C} / \mathrm{min}$ & 16 & 11 & 15 & 15 & 16 \\
\hline & \multirow{3}{*}{ h (-) } & $1^{\circ} \mathrm{C} / \mathrm{min}$ & - & - & 0.083 & 0.090 & 0.089 \\
\hline & & $3^{\circ} \mathrm{C} / \mathrm{min}$ & - & - & 0.061 & 0.072 & 0.073 \\
\hline & & $10^{\circ} \mathrm{C} / \mathrm{min}$ & 0.084 & 0.022 & 0.064 & 0.062 & 0.076 \\
\hline \multirow{9}{*}{ Oxidation } & \multirow{3}{*}{$\mathrm{E}_{0}(\mathrm{~kJ} / \mathrm{mol})$} & $1^{\circ} \mathrm{C} / \mathrm{min}$ & - & - & 211 & 214 & 219 \\
\hline & & $3^{\circ} \mathrm{C} / \mathrm{min}$ & - & - & 215 & 215 & 220 \\
\hline & & $10^{\circ} \mathrm{C} / \mathrm{min}$ & 213 & - & 214 & 213 & 221 \\
\hline & \multirow{3}{*}{$\begin{array}{c}\sigma \\
(\mathrm{kJ} / \mathrm{mol})\end{array}$} & $1^{\circ} \mathrm{C} / \mathrm{min}$ & - & - & 14 & 15 & 15 \\
\hline & & $3{ }^{\circ} \mathrm{C} / \mathrm{min}$ & - & - & 15 & 14 & 15 \\
\hline & & $10^{\circ} \mathrm{C} / \mathrm{min}$ & 17 & - & 16 & 15 & 15 \\
\hline & \multirow{3}{*}{ h (-) } & $1^{\circ} \mathrm{C} / \mathrm{min}$ & - & - & 0.057 & 0.065 & 0.065 \\
\hline & & $3{ }^{\circ} \mathrm{C} / \mathrm{min}$ & - & - & 0.071 & 0.066 & 0.066 \\
\hline & & $10^{\circ} \mathrm{C} / \mathrm{min}$ & 0.102 & - & 0.084 & 0.077 & 0.077 \\
\hline
\end{tabular}

Data demonstrate that for both pyrolysis and oxidation, the effect of the heating rate on $\mathrm{E}_{0}$ and $\sigma$ is negligible. Therefore, every substrate can be associated with one single pair of $\mathrm{E}_{0}$ and $\sigma$, regardless of the heating rate, which agrees with previous studies performed on other biomass substrates [28]. Under both inert and oxidative atmospheres, the Gaussian DAEM adopted does not highlight the effects of both HTC and its severity on the starting feedstock (their maximum relative difference is 3.7\%). This is not surprising: the model basis on the assumption of approximating the entire decomposition profile, which includes more stages, through a one-step profile characterized by a Gaussian distribution. Therefore, the final values of $E_{0}$ and $\sigma$ can be considered as a sort of weighted average among the values of the single components (biomass constituents), i.e., hemicellulosic, lignin-like plus cellulosic compounds, and oil. Probably, the difference in the relative composition of the hydrochars is not enough to affect the final values. In particular, under an inert atmosphere, $E_{0}$ passes from $193 \mathrm{~kJ} / \mathrm{mol}$ of grape seeds to $200-209 \mathrm{~kJ} / \mathrm{mol}$ of hydrochars, while $\sigma$ ranges between 14 and $17 \mathrm{~kJ} / \mathrm{mol}$. Values agree with those reported in the literature on the single components. For example, during pyrolysis, the activation energies usually range in $80-116 \mathrm{~kJ} / \mathrm{mol}$ for hemicellulose, $195-286 \mathrm{~kJ} / \mathrm{mol}$ for cellulose, and $176-300 \mathrm{~kJ} / \mathrm{mol}$ for lignin $[35,42]$. The pyrolysis of oil alone has an $\mathrm{E}_{0}$ of $218 \mathrm{~kJ} / \mathrm{mol}$. With values between 211 and $215 \mathrm{~kJ} / \mathrm{mol}$, the activation energy of oxidation is the same for grape seeds and hydrochars obtained at 180 and $220^{\circ} \mathrm{C}$. Meanwhile, it slightly increases at $220 \mathrm{~kJ} / \mathrm{mol}$ for the $250^{\circ} \mathrm{C}$ hydrochar. 


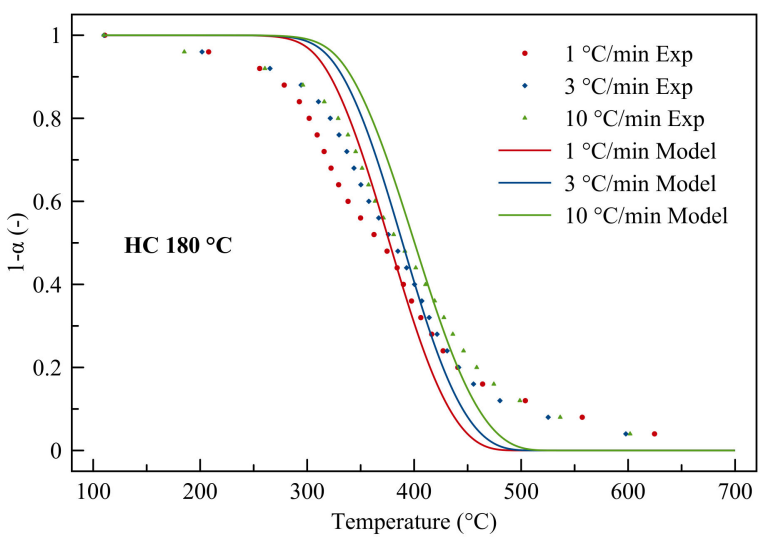

(a)

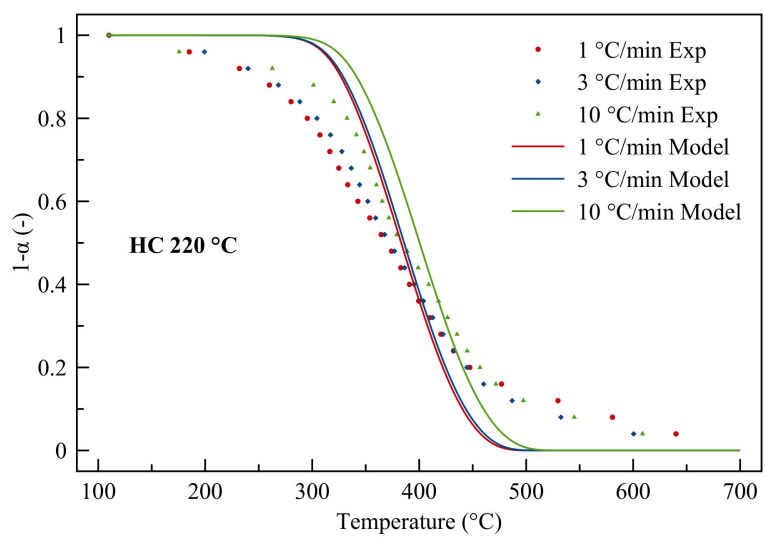

(b)

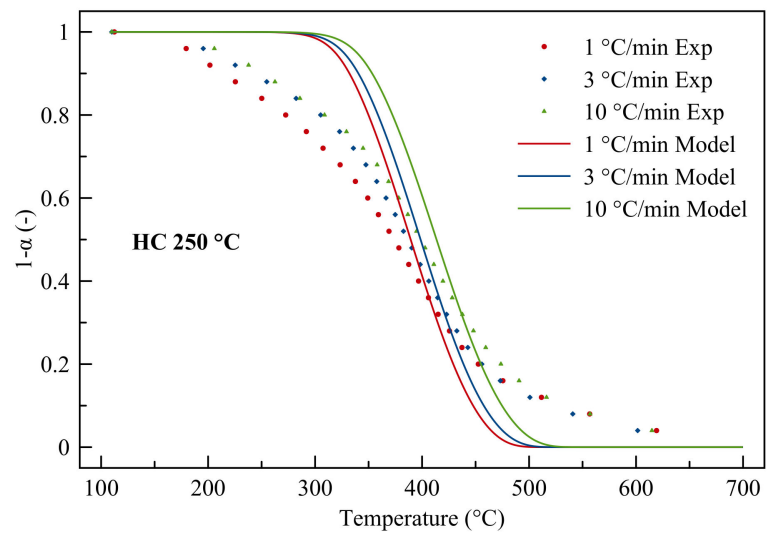

(c)

Figure 5. 1- $\alpha$ vs. temperature: comparison between experimental data (dots) and predicted data (lines) computed through the Gaussian model, during pyrolysis of different samples. (a) hydrochar $180{ }^{\circ} \mathrm{C}$; (b) hydrochar $220^{\circ} \mathrm{C}$; (c) hydrochar $250{ }^{\circ} \mathrm{C}$.

\subsubsection{Miura-Maki Model}

Figure 6 shows the values of E, while Tables S1 and S2 (Supplementary Materials) report the values of both $\mathrm{E}$ and $\mathrm{k}_{0}$ with the correlation coefficient $\mathrm{R}^{2}$. Figure 7 shows the plot of $\ln \left(\beta / \mathrm{T}^{2}\right)$ vs. $-1 / \mathrm{RT}$ at different values of $\alpha$. Each line corresponds to a certain $\alpha$, while the three points on each line correspond to different heating rates. Each $\alpha$ corresponds to a certain temperature and the sequence $\mathrm{T}_{\beta=1{ }^{\circ} \mathrm{C} / \min }<\mathrm{T}_{\beta=3{ }^{\circ} \mathrm{C} / \mathrm{min}} \mathrm{T}_{\beta=10{ }^{\circ} \mathrm{C} / \mathrm{min}}$ has to be respected. The maximum value of conversion for which the correct sequence of temperature was respected is defined with $\alpha_{\max }<1$. This was found in the range of $\alpha 0.1-0.8$ for pyrolysis and $0.1-0.9$ for oxidation. Then, for the valid range of $\alpha, E$ and $\mathrm{k}_{0}$ were determined graphically using the schemes in Figure 7; E is given by the slope of each line for each $\alpha$, while $\mathrm{k}_{0}$ is obtained from the intercept and by applying Equation (13). 


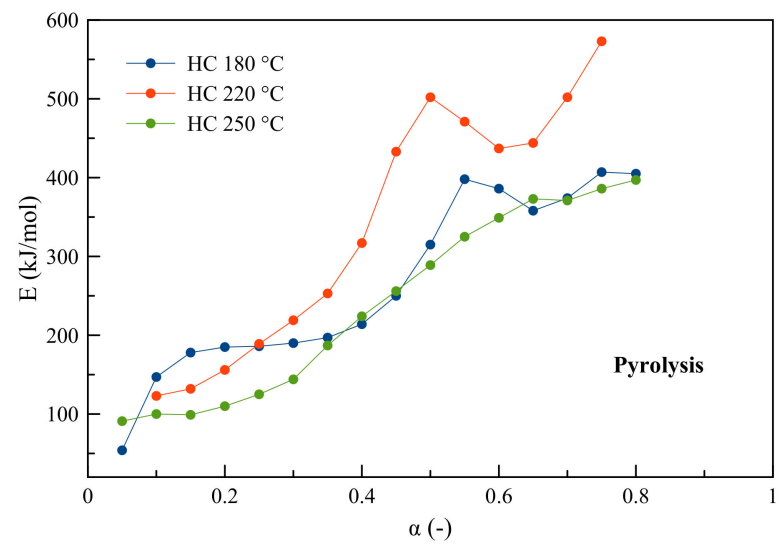

(a)

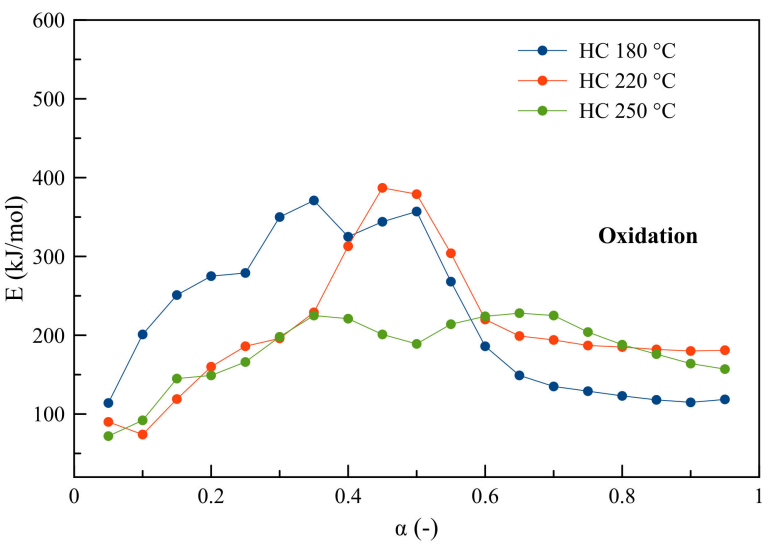

(b)

Figure 6. Distribution of $\mathrm{E}$ at different $\alpha$ of hydrochars, computed through the Miura-Maki model during (a) pyrolysis and (b) oxidation; per mol of dry feedstock.

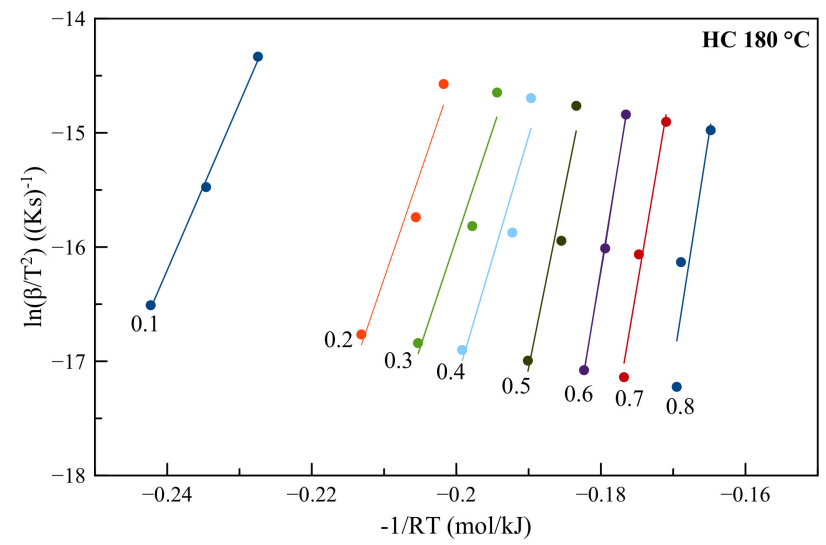

(a)

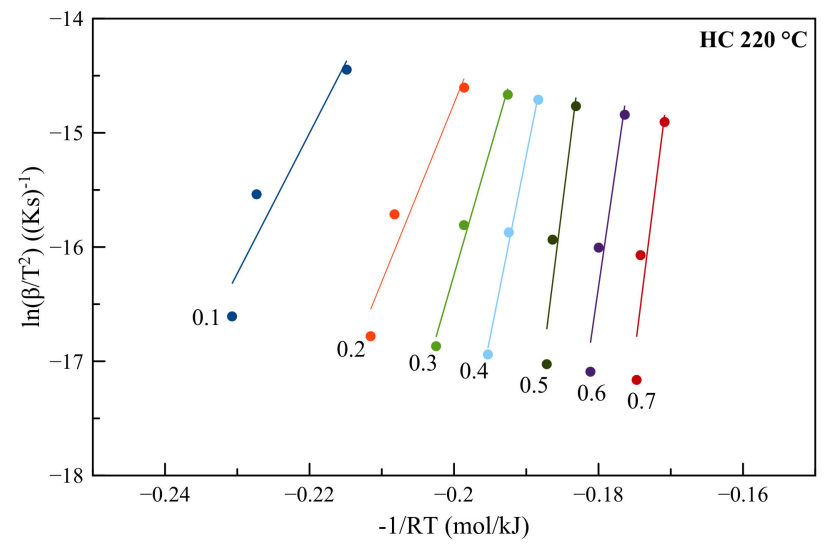

(b)

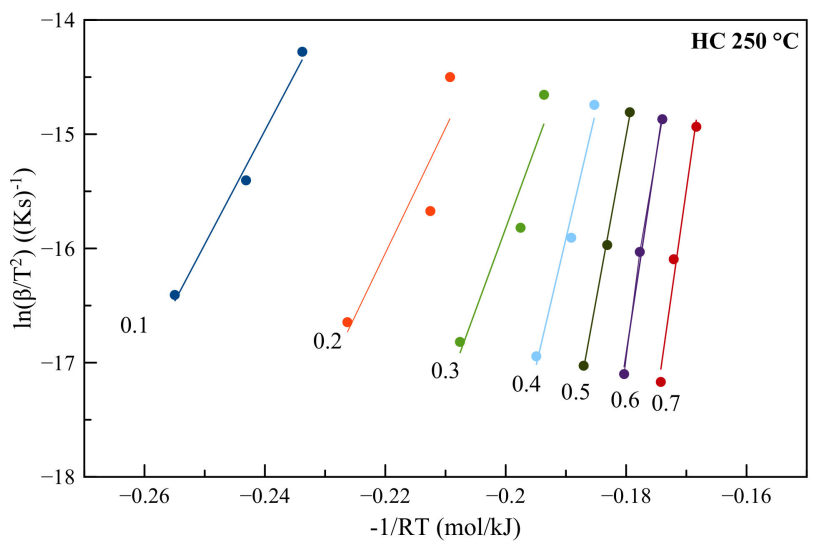

(c)

Figure 7. Miura-Maki diagrams of pyrolysis of: (a) hydrochar $180{ }^{\circ} \mathrm{C}$; (b) hydrochar $220^{\circ} \mathrm{C}$; (c) hydrochar $250{ }^{\circ} \mathrm{C}$.

Under pyrolysis, the fitting is satisfactory, with a $\mathrm{R}^{2}$ always higher than 0.95 , except for one outlier at $\alpha=0.7$ for the $220{ }^{\circ} \mathrm{C}$ hydrochar. Results show that $\alpha$ hugely affects the kinetic parameters. All the hydrochars present an $\mathrm{E}$ that increases with the degree of conversion: it rapidly passes from $100-147 \mathrm{~kJ} / \mathrm{mol}($ at $\alpha=0.1$ ) to $371-386 \mathrm{~kJ} / \mathrm{mol}$ in a 
range of $\alpha 0.6-0.7$. This phenomenon can be explained by the progressive increase of the degree of carbonization with temperature. As pyrolysis proceeds, the biomass undergoes volatilization and is converted into a high-carbon content matrix. This char is more difficult to degrade than the volatile matter and therefore causes a higher E. Generally, values are considerably higher than those commonly found in literature for biomass substrates (for example, for lignin it is $237-267 \mathrm{~kJ} / \mathrm{mol}$, and for pine wood it is $186-271 \mathrm{~kJ} / \mathrm{mol}$ [27]), which can be explained by the nature of the substrate. Meanwhile, $\mathrm{k}_{0}$ reaches its maximum at an $\alpha$ of $0.5-0.6$, with maximum values of $10^{24-27}$ for the 180 and $250^{\circ} \mathrm{C}$ hydrochars and $10^{38}$ for the $220^{\circ} \mathrm{C}$ one.

Figure $6 \mathrm{~b}$ shows how $\mathrm{E}$ of different hydrochars vary during oxidation. For the 180 and $220{ }^{\circ} \mathrm{C}$ hydrochars, E increases up to $\alpha=0.3-0.5$ to values of $357-379 \mathrm{~kJ} / \mathrm{mol}$. Meanwhile, the $250{ }^{\circ} \mathrm{C}$ hydrochar shows a very similar trend to the $220^{\circ} \mathrm{C}$ one up to an $\alpha$ of 0.35 , and then stabilizes at much lower values of $221-225 \mathrm{~kJ} / \mathrm{mol}$. The $180^{\circ} \mathrm{C}$ hydrochar shows higher values of $\mathrm{E}$ at the beginning of the conversion. Therefore, the HTC severity decreases the kinetic parameters of both volatile matter and char produced during the process. Similar trends were observed by Bach et al. [20] on hydrochars produced from wood residues. Meanwhile, pre-exponential factors $\mathrm{k}_{0}$ show a very similar trend to $\mathrm{E}$ (they reach their maxima in correspondence of the maximum of $\alpha$, arriving up to $10^{24-27}$ for the 180 and $220^{\circ} \mathrm{C}$ hydrochars, and $10^{14}$ for the $250{ }^{\circ} \mathrm{C}$ one).

\subsubsection{Comparison and Suggestions for Future Work}

Table 6 reports a comparison table with the average values of $\mathrm{E}, \sigma$, and $\mathrm{k}_{0}$, computed through the Gaussian and Miura-Maki models.

Table 6. Average values of $\mathrm{E}, \sigma$, and $\mathrm{k}_{0}$ computed through the Gaussian and Miura-Maki models $\left(\mathrm{k}_{0}\right.$ constant and equal to $1.67 \times 10^{13} \mathrm{~s}^{-1}$ for the Gaussian model).

\begin{tabular}{|c|c|c|c|c|c|c|c|}
\hline Model & Atmosphere & Parameter & Grape Seeds & Oil & $180^{\circ} \mathrm{C}$ & $\begin{array}{c}\text { Hydrochar } \\
220^{\circ} \mathrm{C}\end{array}$ & $250^{\circ} \mathrm{C}$ \\
\hline \multirow{4}{*}{ Gaussian } & \multirow{2}{*}{ Pyrolysis } & $\mathrm{E}(\mathrm{kJ} / \mathrm{mol})$ & 193 & 218 & 203 & 203 & 206 \\
\hline & & $\sigma(\mathrm{kJ} / \mathrm{mol})$ & 16 & 11 & 15 & 15 & 16 \\
\hline & \multirow{2}{*}{ Oxidation } & $\mathrm{E}(\mathrm{kJ} / \mathrm{mol})$ & 213 & - & 213 & 214 & 220 \\
\hline & & $\sigma(\mathrm{kJ} / \mathrm{mol})$ & 17 & - & 15 & 15 & 15 \\
\hline \multirow{4}{*}{ Miura-Maki } & \multirow{2}{*}{ Pyrolysis } & $\mathrm{E}(\mathrm{kJ} / \mathrm{mol})$ & - & - & 265 & 339 & 239 \\
\hline & & $\mathrm{k}_{0}\left(\mathrm{~s}^{-1}\right)$ & - & - & $7.6 \times 10^{27}$ & $6.0 \times 10^{38}$ & $9.8 \times 10^{24}$ \\
\hline & \multirow{2}{*}{ Oxidation } & $\mathrm{E}(\mathrm{kJ} / \mathrm{mol})$ & - & - & 222 & 215 & 181 \\
\hline & & $\mathrm{k}_{0}\left(\mathrm{~s}^{-1}\right)$ & - & - & $3.4 \times 10^{26}$ & $1.0 \times 10^{26}$ & $2.9 \times 10^{13}$ \\
\hline
\end{tabular}

Due to its starting hypothesis, i.e., approximating the profile with a single Gaussian curve, the Gaussian model does not highlight the effect of the severity of the HTC process on E, which ranges between 193 and $206 \mathrm{~kJ} / \mathrm{mol}$ for pyrolysis. This does not occur for the Miura-Maki model, which assumes a distribution of $\mathrm{E}$ that varies on the entire range leading to more diverse average values. Indeed, the Gaussian approach models a decomposition involving several stages through a single decomposition stage characterized by a Gaussian profile of the activation energy. Therefore, this assumption "averages" the profiles, canceling the differences among the samples obtained at different severities. Meanwhile, the Miura-Maki model avoids this averaging since it does not impose a similar strong assumption on the distribution.

Since the literature lacks the modeling of the kinetics of pyrolysis of hydrochar derived from grape seeds, the comparison of the results obtained was possible considering typical values of activation energy for decomposition of the main constituents of lignocellulosic materials. In particular, cellulose decomposition activation energy ranges between 175 and $279 \mathrm{~kJ} / \mathrm{mol}[21,27,50]$ hemicellulose is in the range $132-186 \mathrm{~kJ} / \mathrm{mol}[27,51,52]$, whereas 
lignin ranges from 62 to $271 \mathrm{~kJ} / \mathrm{mol}$ [27,50-52], with the broadest range. These values seem to prove the consistency of the results obtained in the present work.

In general, the Gaussian model has the advantage of being valid over the entire range of conversion, while the Miura-Maki model requires always that the temperature sequence must be satisfied, an aspect that is not obvious (in this study this occurs only for $\alpha$ in the range of $0.1-0.8$ ). Overall, both the models suffer from a strong starting hypothesis: $\mathrm{k}_{0}$ fixed for the Gaussian model and a strong integral simplification in the Miura-Maki model that can lead to an overestimation of the average values of the kinetics parameters [53].

To improve the prediction, the authors suggest extending the single Gaussian model to a Multi Gaussian, in which the entire decomposition profile is divided into single decomposition peaks, each one approximated by a Gaussian curve [21]. Indeed, the single approach suits well homogeneous substrates (like the oil) characterized by a single decomposition peak, but seems too simple for complex substrates like biomasses. As a result, future works should include a comparison with other kinetics models.

Then, applying other DAEMs (like Kissinger-Akahira-Sunose method and the CoatsRedfern method) on the same feedstock could help to validate the results. Apart from contributing to understanding the mechanisms behind the decomposition, kinetic parameters can help in technological design and optimization. Moving to a larger scale, integration with other modeling techniques is necessary. Among these, it is worth mentioning models that consider the effects of particle distribution and geometry on heat transfer phenomena (like fractal models [54,55]), statistical models [56], and comprehensive computational models [57].

\subsection{Aspen Plus Model}

Figure 8a,c show the trend of heat produced/required as computed by Aspen Plus under pyrolytic and oxidative atmosphere.

Regarding pyrolysis, all samples follow a similar trend, characterized by an exothermic behavior at low temperatures and an endothermic one at high temperatures. Figure 9 reports the trends of the products at different pyrolysis temperatures resulting from the $180{ }^{\circ} \mathrm{C}$ hydrochar (the other samples present the same qualitative trends) and can help to interpret the heat trends. At low temperatures, thermodynamics favors exothermic reactions like char oxidation to $\mathrm{CO}_{2}$ and $\mathrm{CO}$, oxidation of hydrogen, and methanation. Conversely, higher temperatures enhance endothermic reactions, like the Boudouard reaction (and therefore the conversion of $\mathrm{CO}_{2}$ into $\mathrm{CO}$ ), and methane steam reforming (thus the conversion of $\mathrm{CH}_{4}$ and $\mathrm{H}_{2} \mathrm{O}$ to $\mathrm{CO}$ and $\mathrm{H}_{2}$ ). At low temperatures, more carbonized substrates show a higher exothermic behavior due to a higher carbon partial oxidation and methane production (they present a higher $\mathrm{C} / \mathrm{H}$ ratio than less carbonized substrates). Conversely, at higher temperatures, less carbonized samples show a higher endothermic behavior, probably due to the higher production of $\mathrm{CO}$. As expected from its high $\mathrm{C} / \mathrm{O}$ ratio and low volatile matter content, the profile of coal is flatter than hydrochar, and it is always endothermic. The different starting points can be explained by the higher ash content of coal than hydrochars (13.7\% vs. $1.9-2.5 \%)$ : ash, being not reactive, lowers the energy input/output per unit of mass involved. The slight difference in the coal profile with the previous work of our group [40] is due to the different inlet temperatures (isotherm to the reactors here vs. at ambient temperature in [31]). 


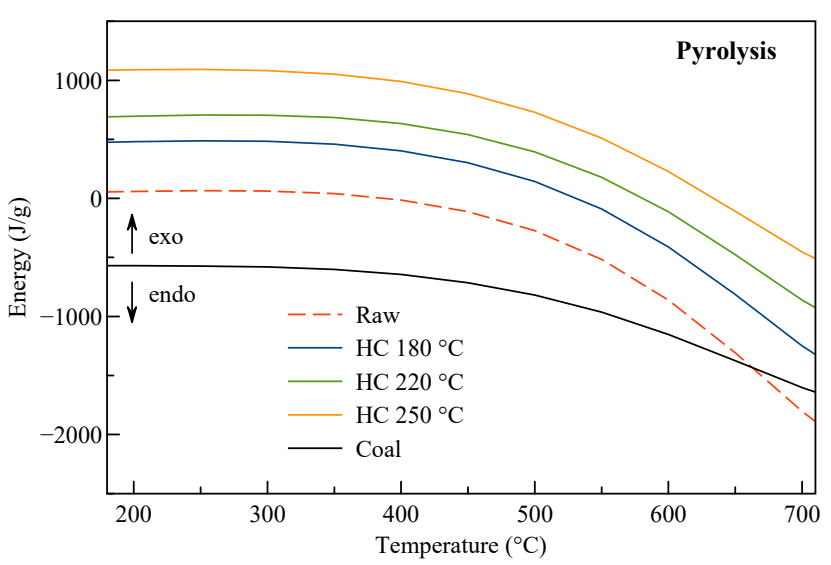

(a)

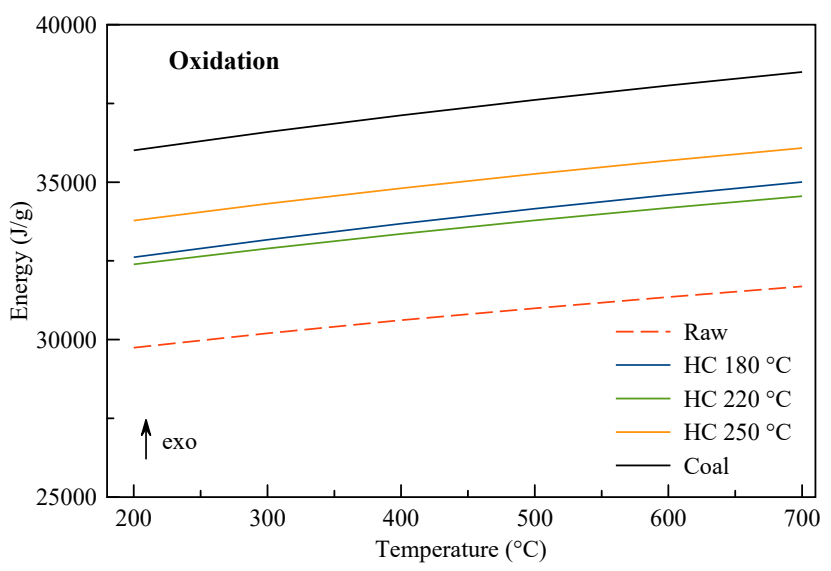

(c)

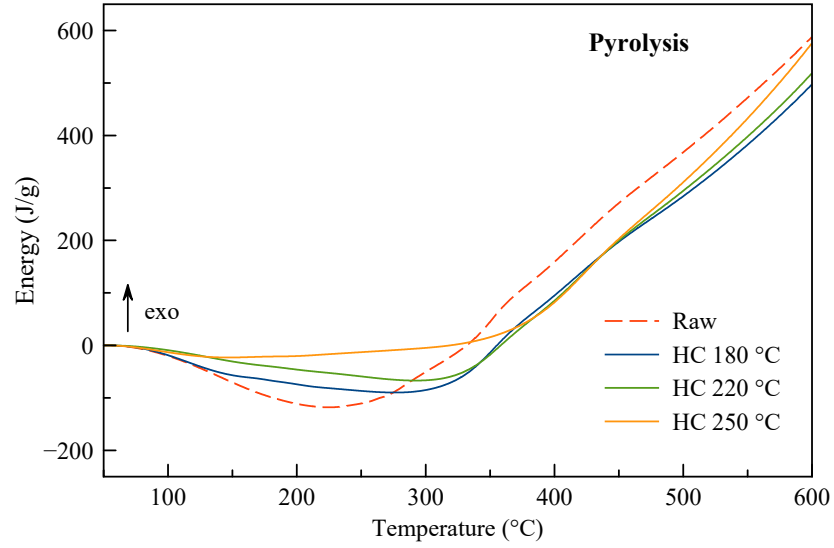

(b)

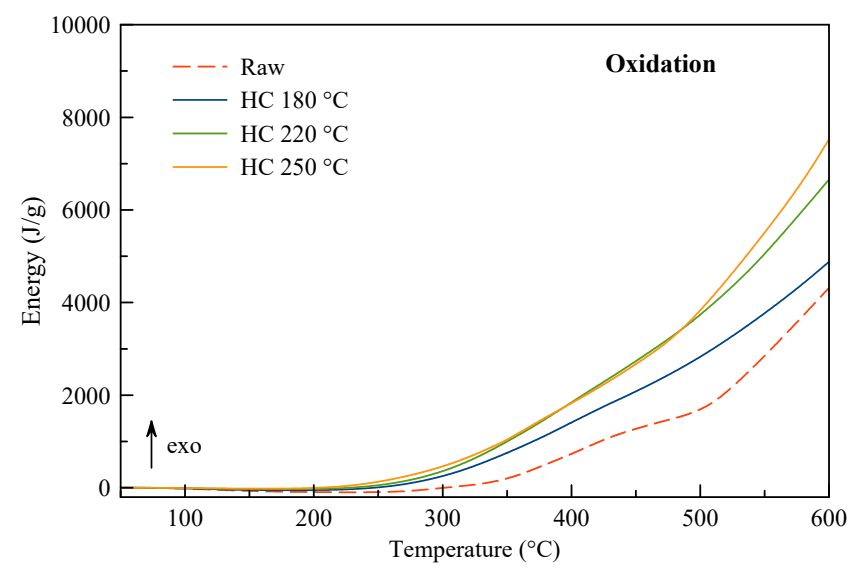

(d)

Figure 8. Energy released $(>0)$ or absorbed $(<0)$ by the samples computed from: (a) Aspen Plus during pyrolysis; (b) DSC data during pyrolysis at $10{ }^{\circ} \mathrm{C} / \mathrm{min}$; (c) Aspen Plus during oxidation; (d) DSC data during oxidation at $10^{\circ} \mathrm{C} / \mathrm{min}$; per grams of dry feedstock.

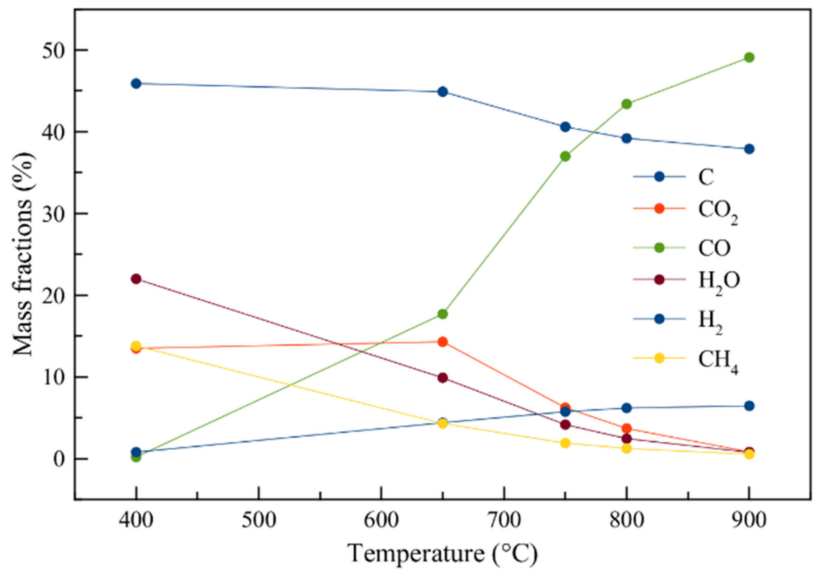

Figure 9. Aspen Plus results: main products from pyrolysis of hydrochar $180^{\circ} \mathrm{C}$.

Besides, Figure 8b shows the progressive integration of pyrolytic DSC data; computing the energy integral is necessary because DSC measures the instantaneous heat flow absorbed or released (which depends on the "history" of the sample due to the thermal program), while thermodynamics considers the energy absorbed or released when converting all the reactants into products at that determined temperature (and therefore the values obtained from thermodynamics do not depend on the thermal history of the sample). Over- 
all, DSC data show a trend towards a cumulative exothermic behavior, whose final value corresponds to the integral reported in Table 4. The different behavior concerning Aspen data can be due to the nature of the thermodynamic approach. Indeed, real systems do not behave as predicted by thermodynamics at low temperatures because of reaction kinetics constraints. Moreover, as previously mentioned, thermodynamics does not consider the "history" of what happened before a certain condition. Indeed, inside the DSC, the starting material progressively undergoes pyrolysis, and the material at every time is the result of what happened before (i.e., the thermal program). In addition, thermodynamics does not consider typical "out of equilibrium" products, like tarry compounds, always present in real systems. Therefore, the thermodynamic approach requires particular attention and criticism before being used.

Regarding oxidation, both thermodynamic and DSC curves are clearly exothermic, with values that progressively increase with temperature. Under both atmospheres, absolute values differ between the Aspen and DSC approaches. This is due to the mass involved: DSC curves measure the energy absorbed/released by an amount of material that progressively decreases with time (the process is occurring), while Aspen predicts the energy absorbed/released by the same mass at every temperature. Since the energy is normalized by the amount of starting feedstock (and not the mass measured at every temperature), the amount of heat computed through the DSC approach is smaller than the Aspen one. Finally, it is interesting to note that in an oxidative environment, and for the whole range of temperature investigated, the thermodynamic approach foresees the complete oxidation of the biomass with the production essentially of $\mathrm{CO}_{2}, \mathrm{H}_{2} \mathrm{O}$, and residual ash (equal to about $2 \%$ of the biomass fed to the reactor, Table 1 ). Conversely, in an oxidative environment in DSC, at the maximum temperature reached of $600{ }^{\circ} \mathrm{C}$, there is still a substantial mass of non-oxidized carbon: the residual mass at $600{ }^{\circ} \mathrm{C}$ is of the order of $30 \%$ (Table 4 ). Through this critical comparison, the two approaches, thermodynamic and DSC, turn out to actually be very distant from each other, which is an aspect worthy of interest.

\section{Conclusions}

This work investigated the kinetic behavior during pyrolysis and oxidation of hydrochars derived from an agro-industrial residue (grape seeds). The topic was approached through experimental techniques (TGA and DSC) that were used to develop two different DAEMs for biomass decomposition. Indeed, there is a certain lack in the literature regarding hydrochar decomposition, especially for the computation of the kinetic parameters. Therefore, this work covers both the experimental aspects and the comparison of two DAEMs using a critical approach. Thermogravimetric analysis and differential scanning calorimetry highlighted the importance of the HTC severity on the decomposition profiles. Indeed, hydrochars obtained at 180 and $220^{\circ} \mathrm{C}$ still decompose with two/three stages (pyrolysis/oxidation) due to the presence of lignocellulosic constituents and oil that only partially degraded during HTC. Meanwhile, the $250{ }^{\circ} \mathrm{C}$ hydrochar shows a more stable profile, with one/two decomposition peaks, highlighting that HTC temperature hugely affected the structure of the biomass. Interestingly, all hydrochars show a certain exothermic behavior during pyrolysis.

DAEMs predicted the kinetic parameters involved during the pyrolysis and oxidation processes, i.e., the activation energy and the pre-exponential factor. The single-stage Gaussian model does not highlight differences among the various hydrochars obtained at different HTC temperatures, with average values of activation energy in the range 203-206 kJ/mol for pyrolysis and 213-220 kJ/mol for oxidation. Actually, the Gaussian DAEM turned out to be unsatisfactory to model complex feedstock such as hydrochars characterized by multi-decomposition peaks. Meanwhile, the Miura-Maki model, even if not applicable over the entire decomposition region, enabled the determination of the distribution of activation energies: the more severe the HTC process, the lower the activation energy values. 


\begin{abstract}
Supplementary Materials: The following supporting information can be downloaded at: https: / / www.mdpi.com/article/10.3390/en15030950/s1, Figure S1: (1- $\alpha$ ) at different temperatures of feedstock during: (a) pyrolysis; (b) oxidation. Heating rate: $10^{\circ} \mathrm{C} / \mathrm{min}$.; Figure S2: Comparison between DTGA and DSC curves during pyrolysis at $10^{\circ} \mathrm{C} / \mathrm{min}$ of: (a) grape seeds and hydrochar $180{ }^{\circ} \mathrm{C}$; (b) hydrochars 220 and $250^{\circ} \mathrm{C}$; Figure S3: Comparison between experimental and predicted data (1- $\alpha$ vs temperature) computed through the Gaussian model, during oxidation of different samples: (a) hydrochar $180{ }^{\circ} \mathrm{C}$; (b) hydrochar $220^{\circ} \mathrm{C}$; (c) hydrochar $250{ }^{\circ} \mathrm{C}$; Table S1: Details of Miura-Maki model, pyrolysis (on a dry basis); Table S2: Details of Miura-Maki model, oxidation (on a dry basis); Gaussian DAEM - MATLAB code.
\end{abstract}

Author Contributions: G.G.: methodology, software, data curation, writing-original draft preparation; G.I.: data curation, visualization, writing — original draft preparation; L.F. (Luca Fambri): experimental planning, writing-review and editing, supervision, project administration; L.F. (Luca Fiori): writing-review and editing, supervision, project administration. All authors have read and agreed to the published version of the manuscript.

Funding: This research received no external funding.

Institutional Review Board Statement: Not applicable.

Informed Consent Statement: Informed consent was obtained from all subjects involved in the study.

Data Availability Statement: Not applicable.

Acknowledgments: All the authors acknowledge Claudia Gavazza for thermal analysis. G.I. acknowledges the financial support provided by the ERICSOL project of the University of Trento, which partially covered her Ph.D. scholarship. All individuals included in this section have consented to the acknowledgement.

Conflicts of Interest: The authors declare no conflict of interest.

\title{
References
}

1. Li, J.; Pan, L.; Suvarna, M.; Tong, Y.W.; Wang, X. Fuel Properties of Hydrochar and Pyrochar: Prediction and Exploration with Machine Learning. Appl. Energy 2020, 269, 115166. [CrossRef]

2. Ahmed, M.; Andreottola, G.; Elagroudy, S.; Negm, M.S.; Fiori, L. Coupling Hydrothermal Carbonization and Anaerobic Digestion for Sewage Digestate Management: Influence of Hydrothermal Treatment Time on Dewaterability and Bio-Methane Production. J. Environ. Manage. 2021, 281, 111910. [CrossRef] [PubMed]

3. De Medeiros, A.D.M.; Da Silva Junior, C.J.G.; De Amorim, J.D.P.; Do Nascimento, H.A.; Converti, A.; De Santana Costa, A.F.; Sarubbo, L.A. Biocellulose for Treatment of Wastewaters Generated by Energy Consuming Industries: A Review. Energies 2021, 14, 1-18. [CrossRef]

4. Yu, C.; Ren, S.; Wang, G.; Xu, J.; Teng, H.; Li, T.; Huang, C.; Wang, C.; Yu, C.; Ren, S.; et al. Kinetic Analysis and Modeling of Maize Straw Hydrochar Combustion Using a Multi- Gaussian-Distributed Activation Energy Model Kinetic Analysis and Modeling of Maize Straw Hydrochar Combustion Using a Multi-Gaussian-Distributed Activation. Energy Model. 2021, 28, 611-620.

5. Zhang, N.; Wang, G.; Zhang, J.; Ning, X.; Li, Y.; Liang, W.; Wang, C. Study on Co-Combustion Characteristics of Hydrochar and Anthracite Coal. J. Energy Inst. 2020, 93, 1125-1137. [CrossRef]

6. Chen, Z.; Hu, M.; Zhu, X.; Guo, D.; Liu, S.; Hu, Z.; Xiao, B.; Wang, J.; Laghari, M. Characteristics and Kinetic Study on Pyrolysis of Five Lignocellulosic Biomass via Thermogravimetric Analysis. Bioresour. Technol. 2015, 192, 441-450. [CrossRef]

7. Chen, J.; Wang, Y.; Lang, X.; Ren, X.; Fan, S. Evaluation of Agricultural Residues Pyrolysis under Non-Isothermal Conditions: Thermal Behaviors, Kinetics, and Thermodynamics. Bioresour. Technol. 2017, 241, 340-348. [CrossRef]

8. Ferrentino, R.; Merzari, F.; Fiori, L.; Andreottola, G. Coupling Hydrothermal Carbonization with Anaerobic Digestion for Sewage Sludge Treatment: Influence of HTC Liquor and Hydrochar on Biomethane Production. Energies 2020, 13, 6262. [CrossRef]

9. Funke, A.; Ziegler, F. Hydrothermal Carbonization of Biomass: A Summary and Discussion of Chemical Mechanisms for Process Engineering. Biofuels, Bioprod. Biorefining 2010, 4, 160-177. [CrossRef]

10. Olszewski, M.P.; Arauzo, P.J.; Wądrzyk, M.; Kruse, A. Py-GC-MS of Hydrochars Produced from Brewer's Spent Grains. J. Anal. Appl. Pyrolysis 2019, 140, 255-263. [CrossRef]

11. Ischia, G.; Cazzanelli, M.; Fiori, L.; Orlandi, M.; Miotello, A. Exothermicity of Hydrothermal Carbonization: Determination of Heat Profile and Enthalpy of Reaction via High-Pressure Differential Scanning Calorimetry. Fuel 2022, 310, 122312. [CrossRef]

12. Ischia, G.; Fiori, L. Hydrothermal Carbonization of Organic Waste and Biomass: A Review on Process, Reactor, and Plant Modeling. Waste and Biomass Valorization 2021, 12, 2797-2824. [CrossRef]

13. Scrinzi, D.; Andreottola, G.; Fiori, L. Composting Hydrochar-OFMSW Digestate Mixtures: Design of Bioreactors and Preliminary Experimental Results. Appl. Sci. 2021, 11, 1-15. [CrossRef] 
14. Lin, J.C.; Mariuzza, D.; Volpe, M.; Fiori, L.; Ceylan, S.; Goldfarb, J.L. Integrated Thermochemical Conversion Process for Valorizing Mixed Agricultural and Dairy Waste to Nutrient-Enriched Biochars and Biofuels. Bioresour. Technol. 2021, 328, 124765. [CrossRef]

15. Hu, Q.; Yang, H.; Xu, H.; Wu, Z.; Lim, C.J.; Bi, X.T.; Chen, H. Thermal Behavior and Reaction Kinetics Analysis of Pyrolysis and Subsequent In-Situ Gasification of Torrefied Biomass Pellets. Energy Convers. Manag. 2018, 161, 205-214. [CrossRef]

16. Román, S.; Libra, J.; Berge, N.; Sabio, E.; Ro, K.; Li, L.; Ledesma, B.; Alvarez, A.; Bae, S. Hydrothermal Carbonization: Modeling, Final Properties Design and Applications: A Review. Energies 2018, 11, 216. [CrossRef]

17. Sharma, H.B.; Panigrahi, S.; Dubey, B.K. Hydrothermal Carbonization of Yard Waste for Solid Bio-Fuel Production: Study on Combustion Kinetic, Energy Properties, Grindability and Flowability of Hydrochar. Waste Manag. 2019, 91, 108-119. [CrossRef]

18. Islam, M.A.; Kabir, G.; Asif, M.; Hameed, B.H. Combustion Kinetics of Hydrochar Produced from Hydrothermal Carbonisation of Karanj (Pongamia Pinnata) Fruit Hulls via Thermogravimetric Analysis. Bioresour. Technol. 2015, 194, 14-20. [CrossRef]

19. He, C.; Giannis, A.; Wang, J.-Y. Conversion of Sewage Sludge to Clean Solid Fuel Using Hydrothermal Carbonization: Hydrochar Fuel Characteristics and Combustion Behavior. Appl. Energy 2013, 111, 257-266. [CrossRef]

20. Bach, Q.V.; Tran, K.Q.; Skreiberg, Ø. Combustion Kinetics of Wet-Torrefied Forest Residues Using the Distributed Activation Energy Model (DAEM). Appl. Energy 2017, 185, 1059-1066. [CrossRef]

21. Zhang, J.; Chen, T.; Wu, J.; Wu, J. Multi-Gaussian-DAEM-Reaction Model for Thermal Decompositions of Cellulose, Hemicellulose and Lignin: Comparison of N2 and CO2 Atmosphere. Bioresour. Technol. 2014, 166, 87-95. [CrossRef]

22. Vand, V. A Theory of the Irreversible Electrical Resistance Changes of Metallic Films Evaporated in Vacuum. Proc. Phys. Soc. 1943, 55, 222-246. [CrossRef]

23. Wang, S.; Dai, G.; Yang, H.; Luo, Z. Lignocellulosic Biomass Pyrolysis Mechanism: A State-of-the-Art Review. Prog. Energy Combust. Sci. 2017, 62, 33-86. [CrossRef]

24. Radojević, M.; Janković, B.; Jovanović, V.; Stojiljković, D.; Manić, N. Comparative Pyrolysis Kinetics of Various Biomasses Based on Model-Free and DAEM Approaches Improved with Numerical Optimization Procedure. PLoS ONE 2018, 13, 1-25. [CrossRef]

25. Hameed, S.; Sharma, A.; Pareek, V.; Wu, H.; Yu, Y. A Review on Biomass Pyrolysis Models: Kinetic, Network and Mechanistic Models. Biomass Bioenergy 2019, 123, 104-122. [CrossRef]

26. White, J.E.; Catallo, W.J.; Legendre, B.L. Biomass Pyrolysis Kinetics: A Comparative Critical Review with Relevant Agricultural Residue Case Studies. J. Anal. Appl. Pyrolysis 2011, 91, 1-33. [CrossRef]

27. Cai, J.; Wu, W.; Liu, R.; Huber, G.W. A Distributed Activation Energy Model for the Pyrolysis of Lignocellulosic Biomass. Green Chem. 2013, 15, 1331-1340. [CrossRef]

28. Fiori, L.; Valbusa, M.; Lorenzi, D.; Fambri, L. Modeling of the Devolatilization Kinetics during Pyrolysis of Grape Residues. Bioresour. Technol. 2012, 103, 389-397. [CrossRef]

29. Basso, D.; Weiss-Hortala, E.; Patuzzi, F.; Baratieri, M.; Fiori, L. In Deep Analysis on the Behavior of Grape Marc Constituents during Hydrothermal Carbonization. Energies 2018, 11, 1379. [CrossRef]

30. Cai, J.M.; Bi, L.S. Kinetic Analysis of Wheat Straw Pyrolysis Using Isoconversional Methods. J. Therm. Anal. Calorim. 2009, 98, 325. [CrossRef]

31. Branca, C.; Albano, A.; Di Blasi, C. Critical Evaluation of Global Mechanisms of Wood Devolatilization. Thermochim. Acta 2005, 429, 133-141. [CrossRef]

32. Ischia, G.; Orlandi, M.; Fendrich, M.A.; Bettonte, M.; Merzari, F.; Miotello, A.; Fiori, L. Realization of a Solar Hydrothermal Carbonization Reactor: A Zero-Energy Technology for Waste Biomass Valorization. J. Environ. Manage. 2020. [CrossRef] [PubMed]

33. Miura, K.; Maki, T. A Simple Method for Estimating $\mathrm{f}(\mathrm{E})$ and $\mathrm{K} 0(\mathrm{E})$ in the Distributed Activation Energy Model. Energy and Fuels 1998, 12, 864-869. [CrossRef]

34. Gao, L.; Volpe, M.; Lucian, M.; Fiori, L.; Goldfarb, J.L. Does Hydrothermal Carbonization as a Biomass Pretreatment Reduce Fuel Segregation of Coal-Biomass Blends during Oxidation? Energy Convers. Manag. 2019, 181, 93-104. [CrossRef]

35. Miura, K. A New and Simple Method to Estimate $\mathrm{f}(\mathrm{E})$ and $\mathrm{K} 0(\mathrm{E})$ in the Distributed Activation Energy Model from Three Sets of Experimental Data. Energy and Fuels 1995, 9, 302-307. [CrossRef]

36. Coats, A.W.; Redfern, J.P. Kinetic Parameters from Thermogravimetric Data. Nature 1964, 201, 68-69. [CrossRef]

37. Fischer, P.E.; Jou, C.S.; Gokalgandhi, S.S. Obtaining the Kinetic Parameters from Thermogravimetry Using a Modified Coats and Redfern Technique. Ind. Eng. Chem. Res. 1987, 26, 1037-1040. [CrossRef]

38. Anthony, D.B.; Howard, J.B. Coal Devolatilization and Hydrogastification. AIChE J. 1976, 22, 625-656. [CrossRef]

39. Güneş, M.; Güneş, S. A Direct Search Method for Determination of DAEM Kinetic Parameters from Nonisothermal TGA Data (Note). Appl. Math. Comput. 2002, 130, 619-628. [CrossRef]

40. Ischia, G.; Fiori, L.; Gao, L.; Goldfarb, J.L. Valorizing Municipal Solid Waste via Integrating Hydrothermal Carbonization and Downstream Extraction for Biofuel Production. J. Clean. Prod. 2021, 289, 125781. [CrossRef]

41. Spanghero, M.; Salem, A.Z.M.; Robinson, P.H. Chemical Composition, Including Secondary Metabolites, and Rumen Fermentability of Seeds and Pulp of Californian (USA) and Italian Grape Pomaces. Anim. Feed Sci. Technol. 2009, 152, 243-255. [CrossRef]

42. Moldes, D.; Gallego, P.P.; Rodríguez Couto, S.; Sanromán, A. Grape Seeds: The Best Lignocellulosic Waste to Produce Laccase by Solid State Cultures of Trametes Hirsuta. Biotechnol. Lett. 2003, 25, 491-495. [CrossRef]

43. Hubble, A.H.; Goldfarb, J.L. Synergistic Effects of Biomass Building Blocks on Pyrolysis Gas and Bio-Oil Formation. J. Anal. Appl. Pyrolysis 2021, 156, 105100. [CrossRef] 
44. Volpe, M.; Fiori, L. From Olive Waste to Solid Biofuel through Hydrothermal Carbonisation: The Role of Temperature and Solid Load on Secondary Char Formation and Hydrochar Energy Properties. J. Anal. Appl. Pyrolysis 2017, 124, 63-72. [CrossRef]

45. Mackul'ak, T.; Prousek, J.; Olejníková, P.; Bodík, I. Slovak Society of Chemical Engineering Institute of Chemical and Environmental Engineering Slovak University of Technology in Bratislava. Direct 2010, 1407-1412.

46. Volpe, M.; Goldfarb, J.L.; Fiori, L. Hydrothermal Carbonization of Opuntia Ficus-Indica Cladodes: Role of Process Parameters on Hydrochar Properties. Bioresour. Technol. 2018, 247, 310-318. [CrossRef]

47. Guo, S.; Dong, X.; Wu, T.; Shi, F.; Zhu, C. Characteristic Evolution of Hydrochar from Hydrothermal Carbonization of Corn Stalk. J. Anal. Appl. Pyrolysis 2015, 116, 1-9. [CrossRef]

48. Purnomo, C.W.; Castello, D.; Fiori, L. Granular Activated Carbon from Grape Seeds Hydrothermal Char. Appl. Sci. 2018, 8, 1-16. [CrossRef]

49. Diaz, E.; Manzano, F.; Villamil, J.A.; Rodriguez, J.; Mohedano, A. Low-Cost Activated Grape Seed-Derived Hydrochar through Hydrothermal Carbonization and Chemical Activation for Sulfamethoxazole Adsorption. Appl. Sci. 2019, 9, 5127. [CrossRef]

50. Jiang, G.; Nowakowski, D.J.; Bridgwater, A.V. A Systematic Study of the Kinetics of Lignin Pyrolysis. Thermochim. Acta 2010, 498, 61-66. [CrossRef]

51. Wang, S.; Ru, B.; Lin, H.; Sun, W.; Luo, Z. Pyrolysis Behaviors of Four Lignin Polymers Isolated from the Same Pine Wood. Bioresour. Technol. 2015, 182, 120-127. [CrossRef] [PubMed]

52. Gomez, I.J.; Arnaiz, B.; Cacioppo, M.; Arcudi, F.; Prato, M. Nitrogen-Doped Carbon Nanodots for Bioimaging and Delivery of Paclitaxel. J. Mater. Chem. B 2018, 6, 5540-5548. [CrossRef] [PubMed]

53. Cai, J.; Li, T.; Liu, R. A Critical Study of the Miura-Maki Integral Method for the Estimation of the Kinetic Parameters of the Distributed Activation Energy Model. Bioresour. Technol. 2011, 102, 3894-3899. [CrossRef] [PubMed]

54. Xu, P.; Yu, B. The Scaling Laws of Transport Properties for Fractal-like Tree Networks. J. Appl. Phys. 2006, 100, 104906. [CrossRef]

55. Liang, M.; Fu, C.; Xiao, B.; Luo, L.; Wang, Z. A Fractal Study for the Effective Electrolyte Diffusion through Charged Porous Media. Int. J. Heat Mass Transf. 2019, 137, 365-371. [CrossRef]

56. Mäkelä, M.; Yoshikawa, K. Simulating Hydrothermal Treatment of Sludge within a Pulp and Paper Mill. Appl. Energy 2016, 173, 177-183. [CrossRef]

57. Álvarez-Murillo, A.; Sabio, E.; Ledesma, B.; Román, S.; González-García, C.M. Generation of Biofuel from Hydrothermal Carbonization of Cellulose. Kinetics Modelling. Energy 2016, 94, 600-608. [CrossRef] 